\title{
Material Flows Resulting from Large Scale Deployment of Wind Energy in Germany
}

Till Zimmermann ${ }^{1,2, *}$, Max Rehberger ${ }^{1}$ and Stefan Gößling-Reisemann ${ }^{1,2}$

1 Department of Technological Design and Development, Faculty of Production Engineering, University of Bremen, Bremen D-28359, Germany; E-Mails: max.rehberger@gmail.com (M.R.); sgr@uni-bremen.de (S.G.-R.)

2 ARTEC-Research Center for Sustainability Studies, Bremen D-28359, Germany

* Author to whom correspondence should be addressed; E-Mail: tillz@uni-bremen.de; Tel.: +49-421-218-64893; Fax: +49-421-218-98-64893.

Received: 16 June 2013; in revised form: 12 August 2013 / Accepted: 14 August 2013 / Published: 27 August 2013

\begin{abstract}
The ambitious targets for renewable energies in Germany indicate that the steady growth of installed capacity of the past years will continue for the coming decades. This development is connected with significant material flows - primary material demand as well as secondary material flows. These flows have been analyzed for Germany up to the year 2050 using a statistical model for the turbines' discard patterns. The analysis encompasses the flows of bulk metals, plastics, and rare earths (required for permanent magnets in gearless converters). Different expansion scenarios for wind energy are considered as well as different turbine technologies, future development of hub height and rotor diameter, and an enhanced deployment of converters located offshore. In addition to the direct material use, the total material requirement has been calculated using the material input per service unit (MIPS) concept. The analysis shows that the demand for iron, steel, and aluminum will not exceed around $6 \%$ of the current domestic consumption. The situation for rare earths appears to be different with a maximum annual neodymium demand for wind energy converters corresponding to about a quarter of the overall 2010 consumption. It has been shown that by efficiently utilizing secondary material flows a net material demand reduction of up to two thirds by 2050 seems possible, (i.e., if secondary material flows are fully used to substitute primary material demand).
\end{abstract}


Keywords: material flows; MFA; wind energy; Weibull distribution; material demand; secondary materials; renewable energies

\section{Background and Objectives}

The installed capacity of wind energy is growing rapidly. Over the past 15 years, wind energy has undergone a rapid expansion in Germany, the European Union (EU), and globally. Worldwide, the installed wind energy capacity increased from $6100 \mathrm{MW}$ in 1996 to about 238,000 MW in 2011 [1]. In the EU, wind energy converters accounted for $21.4 \%$ (=9616 MW) of all newly installed capacity in 2011, representing the third biggest share after solar PV (46.7\%) and gas (21.6\%) [2]. Within the EU, Germany has been the largest market with an installation of almost $2100 \mathrm{MW}$ in 2011 [2]. When looking at a 10 year period, the rapid expansion of wind energy becomes even more evident: while the share of wind energy in the EU's capacity mix was about $2 \%$ in the year $2000(=12,887 \mathrm{MW})$ it accounted for over $10 \%(=93,957 \mathrm{MW})$ in 2011 [2]. Figure 1 shows the development of installed capacity over a 15 year time period for Germany, the EU, and globally.

Figure 1. Accumulated installed wind energy capacity (based on [1-3]).

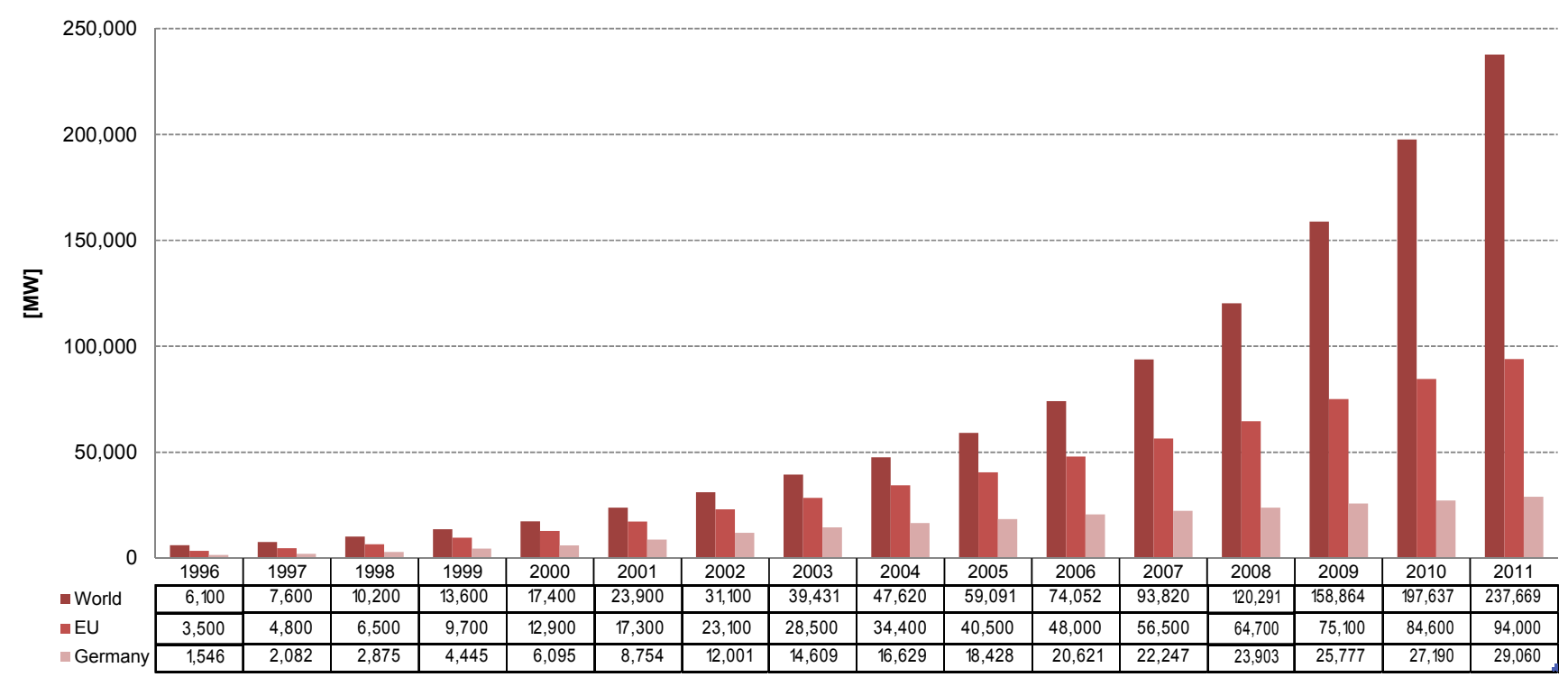

When we look at the ambitious targets for renewable energies in Germany $50 \%$ of the gross electricity consumption in 2030 and $80 \%$ in 2050) it seems very likely that this expansion is going to continue for the coming decades. Current studies conducted on behalf of the German government estimate an installed wind capacity of over $80 \mathrm{GW}$ in 2050 and an annual installation of up to $1550 \mathrm{MW}$ per year [4]. Thirty gigawatts hereof are expected to be located offshore.

This development is evidently connected with significant material flows, including secondary materials from converters reaching their end of life. The objective of the work we present here has been to quantify these flows under consideration of different growth scenarios and possible future technological developments. In order to realistically predict secondary material flows, the Weibull distribution has been used to model the converters' discard patterns. The work focuses on Germany 
and assesses the material flows up to the year 2050. While the first part of the analysis centers around the direct material use (and the resulting stocks and secondary material flows), the second part uses the material input per service unit (MIPS) concept to determine the total material requirement, which accounts for both, the life-cycle-wide primary material input for the construction and maintenance of the wind turbines and other materials moved in nature, but not incorporated in the final product.

\section{Methodological Development and Application}

In the literature, there are only a few studies dealing with the material flow analysis of large scale wind energy deployment. A recent study for Germany, with a focus on material demand, was performed by the Wuppertal Institute [5], and another one, for the global adoption of wind energy with a focus on environmental impacts, was performed by Arvesen and Hertwich [6]. Necessary ingredients for such studies are: (i) a detailed account of the material composition of wind energy converters (WEC), and (ii) scenarios for the uptake of wind energy in the respective region. The latter ingredient has been described in much detail for many parts of the world; see below for scenarios relevant for Germany. The first ingredient, i.e., the material composition of single wind energy converters is also described in the literature, mainly in the context of life-cycle assessment studies [7-18]. However, the material composition is usually analysed for specific existing types of wind energy converters (WEC), not for broader classes of WEC, and only very little is known about the future trends in this respect. For our assessment, we therefore had to combine the existing knowledge on material composition with trends in WEC technology and turbine size.

Based on the above observation regarding the available literature and state of knowledge, the analysis of the material flows resulting from wind energy deployment in Germany has been carried out in several steps. At first, a list of materials for further analysis has been defined and a classification of wind energy converters (WEC) has been developed. In a second step, inventory data has been collected based on existing studies and literature. Data gaps have been closed by applying methods of up-scaling and transferring data from one WEC type to another in order to get the required inventory data for all defined wind turbine types. Annual figures on wind energy installations in Germany have been obtained from publicly available statistics and - for the future-from different scenarios. Here, several scenarios from governmental institutions and non-governmental organizations (NGOs) have been evaluated. From these a reference scenario and three other scenarios have been selected for further analysis. Data gaps in these scenarios were closed by interpolation. Regarding future technological changes in wind turbine technology, assumptions regarding possible developments have been made based on relevant publications, e.g., technology forecasts, information from manufacturers and other studies. The turbines' lifespans and replacements have been modeled statistically using the Weibull distribution function and assuming an average lifespan of twenty years. Based on this, the metal demand for the years 1990 to 2050 and the secondary material flows from year 2012 onwards have been calculated. Subsequently, the life-cycle-wide material input has been calculated by applying material input (MI) values to the direct material demand calculated for the reference scenario. 


\subsection{Selection of Material}

The relevant materials have been selected based on the literature on inventory data of wind turbines. This screening resulted in a list of potentially relevant materials that are shown in Figure 2. A cut-off criterion has been applied and all materials with less than one weight per cent have been excluded. In a second step, the criticality of the excluded materials has been regarded [19,20], and particularly critical metals - the rare earth metals neodymium and dysprosium - have been added to the list of relevant materials.

Figure 2. Materials used in wind energy converters (WEC) by main components [7-10].

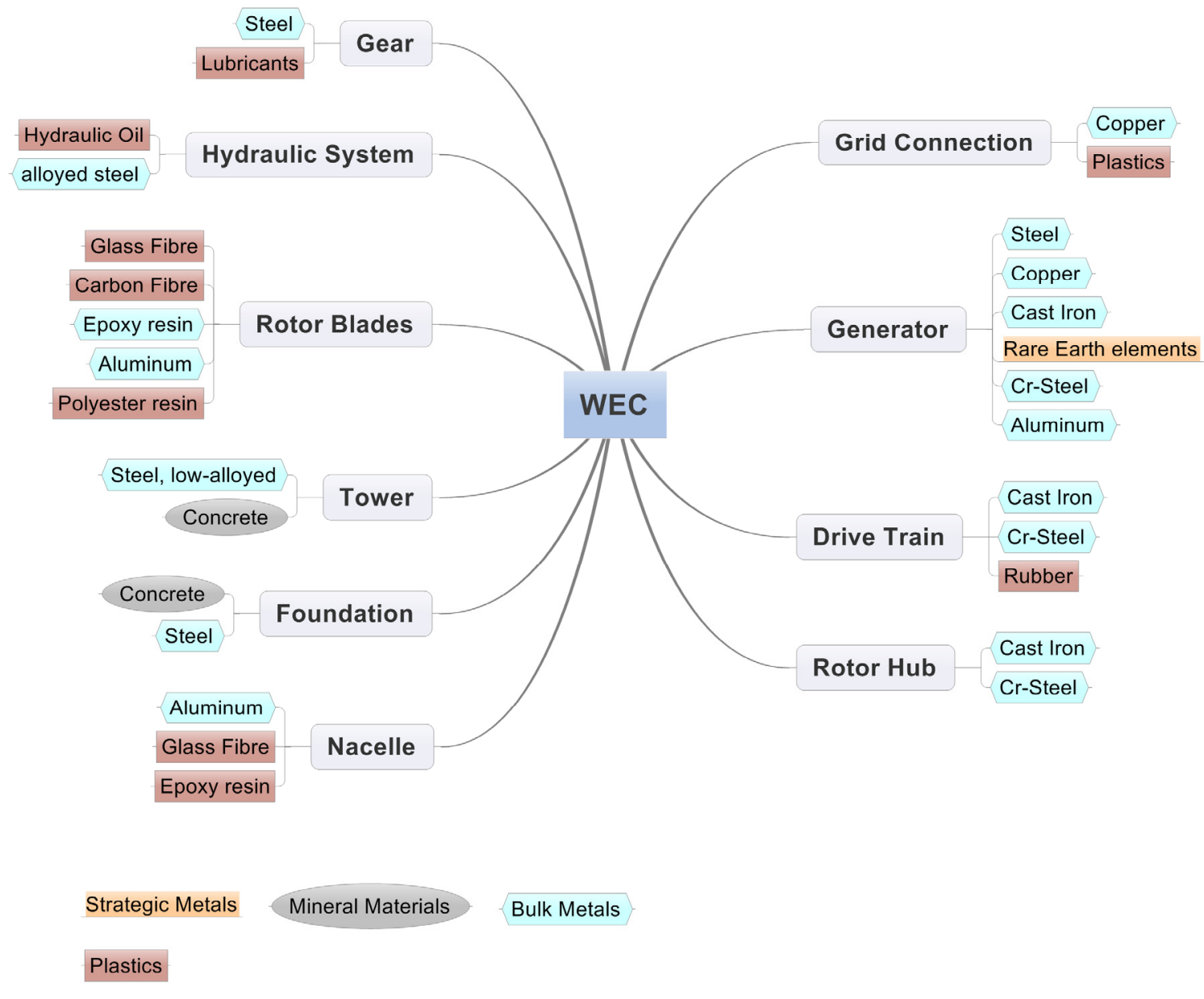

As a result, the materials shown below have been selected for further analysis.

- Mineral materials: Concrete;

- Bulk metals: Iron, steel, aluminum, copper;

- $\quad$ Plastics: CFRP, GFRP, PVC, PU, PE;

- $\quad$ Strategic metals: Rare Earth elements (Nd, Dy).

An aggregation into material groups has been carried out for a streamlined assessment. Criteria for the grouping were common chemical characteristics and related manufacturing and disposal processes. This led to a differentiation of mineral materials, bulk metals, plastics, and strategic metals. However, in the following, copper is reported separately. 


\subsection{Classification of $W E C$}

The classification of wind turbines considers the location (onshore, offshore), technology (especially drive-train technology) and converter size and has been done in consideration of relevant differences in the specific material demand. The classification is shown in Figure 3.

Figure 3. Classification for wind turbines. Offshore classification accordingly. Abbreviations explained in main text.

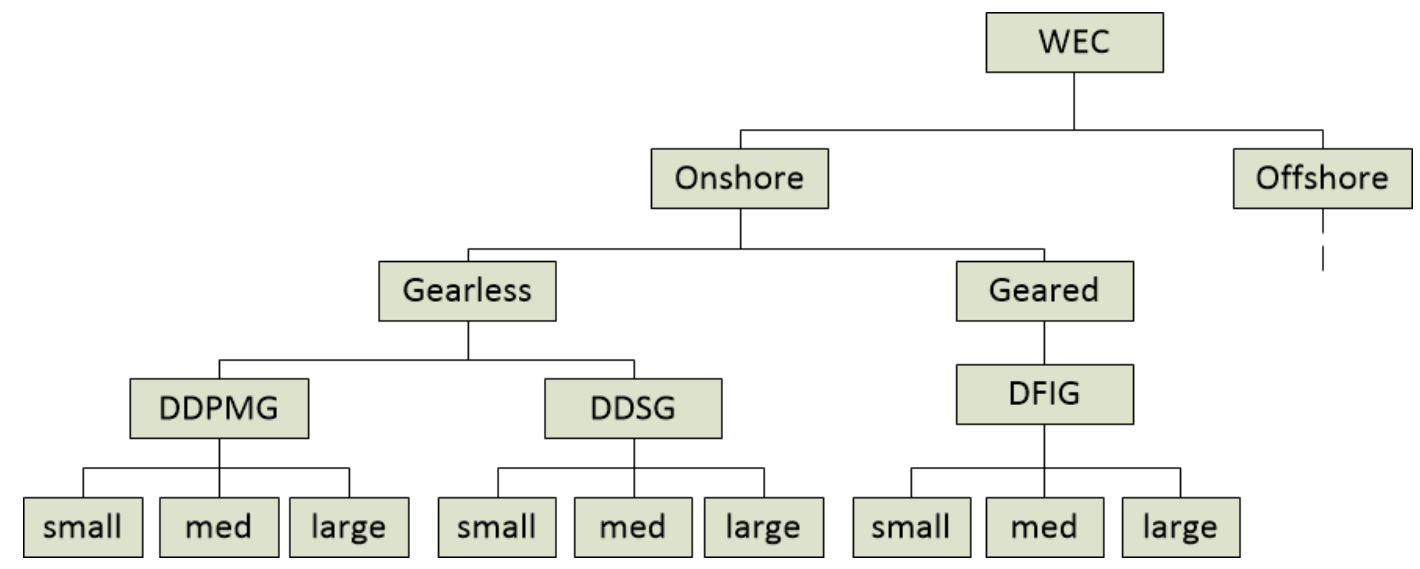

The figure shows only the differentiation for onshore converters; the classification for offshore converters has been done accordingly, except that the size denominations (small, medium, large) represent higher power ratings than in the onshore case. Regarding their specific material demand the main difference between offshore and onshore WECs is their respective foundation technology. Onshore WECs mostly use concrete foundations while offshore converters are installed on steel structures. Another distinction has to be made between gearless and geared converters as there is a general difference in components and generator technology. In geared converters the low rotational speed of the rotor is converted into a higher rotating speed to drive the generator. Commonly, doubly fed induction generators (DFIG) are used. In gearless wind turbine concepts, however, the low rotor speed is used directly to power a specially designed low-speed generator not requiring a gear-box. Gearless generator concepts need to be further distinguished into permanent-magnet-generators (DDPMG) and doubly fed synchronous generators (DDSG) which differ in the electric field generation.

The differences in specific material demand resulting from the technical diversity of wind turbines need to be considered when making estimations of the total material demand. While onshore wind turbines require a lot more concrete for the foundations, a higher percentage of steel is needed for the construction of offshore turbines. Apart from that, onshore and offshore turbines are assessed analogously. In the geared-generator-concept material demand for a gearbox must be considered in contrast to direct-driven turbines. Additionally, the nacelle design of each type of turbine leads to different specific material demand. The generator itself is dominated by copper demand in DDSG WECs while DDPMG have a significant demand of rare earth materials.

For each technology type we distinguish between three different size classes, small, medium, and large. Onshore, these classes are defined according to a classification developed by the German Wind Energy Institute (DEWI) [21]. Offshore, the present situation and forecasts have been taken into account for assigning rated power to each size class. The results of the classification are shown in Table 1. 
Table 1. Size classes and rated power for the classification of onshore and offshore wind energy converters (WEC).

\begin{tabular}{ccc}
\hline Size class & Rating onshore (MW) & Rating offshore (MW) \\
\hline Small & $\leq 2$ & $\leq 5$ \\
Medium & $>2$ and $<3$ & $>5$ and $<12$ \\
Large & $\geq 3$ & $\geq 12$ \\
\hline
\end{tabular}

\subsection{Inventory Analysis}

The collection of inventory data has been carried out in accordance with the wind turbine classification. The data has been collected component-by-component, i.e., not for each converter class as a whole but for every component. The components being distinguished are the foundation, tower, rotor, generator, gear box, and nacelle. Data has been obtained from life-cycle assessment (LCA) studies, from wind turbine manufacturers and other technical papers; see below for details. Existing data gaps have then been closed by up- or downscaling of components from one size class to another or by transferring component material compositions from one turbine class to another.

\subsubsection{Determining Material Demand}

Data on the direct material demand of wind turbines is available in various publications and LCA studies. A screening of these publications has been performed focusing on the differences between the considered wind turbine types.

Some turbine manufacturers, like Vestas, frequently publish LCA data of their current product range including inventory data on different levels of aggregation (see [9-12]). The majority of onshore DFIG wind turbines can be covered by using these publications. Additionally, data for DDSG turbines was available at least for turbines of 2 and $2.3 \mathrm{MW}$ [13]. Additional data was taken from $[7,8,14-18,22-24]$.

Data gaps occurred mainly on turbines following the DDPMG generator principle. For offshore turbines significantly less data is available which required further steps to close data gaps. How these data gaps were treated is described in Section 2.3.3.

In order to account for production waste, correction factors reflecting the material efficiencies in production and manufacturing stages have been included in the calculations and the material demand data were corrected accordingly. These factors are based on several publications [13,15,25-27]. Production wastes with full (i.e., closed loop) recyclability using present day technologies were disregarded. Furthermore, material demand occurring during the use phase (including maintenance and replacement of components) has also been included by applying correction factors to the initial material demand. The assumptions regarding the life spans of single components are based on [26,28-30]. Both corrections to the direct material demand are shown in Table 2. Table 2a shows both, material input per $\mathrm{kg}$ mass of the final product and the assumed in-process recycling rate of the used material. In Table $2 \mathrm{~b}$ the assumed component exchange rates (per lifespan) of different wind turbine types are shown (example: statistically there are 0.3 generators exchanged per lifespan of one DFIG wind turbine). 
Table 2. (a) Correction factors due to production loss; and (b) component exchange rates.

\begin{tabular}{|c|c|c|c|}
\hline Material & \multicolumn{2}{|c|}{ Material efficiency factors $(\mathrm{kg} / \mathrm{kg})$} & Recycling rate \\
\hline Bulk metals & \multicolumn{2}{|c|}{1.14} & $95 \%$ \\
\hline Plastics & \multicolumn{2}{|c|}{1.30} & $0 \%$ \\
\hline Concrete & \multicolumn{2}{|c|}{1.00} & $0 \%$ \\
\hline Strategic metals & \multicolumn{2}{|c|}{1.00} & $0 \%$ \\
\hline Copper & \multicolumn{2}{|c|}{1.04} & $95 \%$ \\
\hline \multicolumn{4}{|c|}{ (a) } \\
\hline \multirow{2}{*}{ Component } & \multicolumn{3}{|c|}{ Component exchanges (per lifetime) } \\
\hline & DDPMG & DDSG & DFIG \\
\hline Rotor & 0.5 & 0.5 & 0.5 \\
\hline Gear & - & - & 0.3 \\
\hline Generator & 0 & 0 & 0.3 \\
\hline
\end{tabular}

(b)

\subsubsection{Upscaling}

The term "upscaling" is widely used in the context of wind turbine design to describe size and mass changes of main components of wind turbines when key parameters change, such as rotor diameter or nominal power. In order to mathematically formulate these correlations, Caduff et al. carried out a study on how these parameters changed in the past given constant turbine growth [31]. Regarding 12 onshore turbines with nominal powers ratings ranging from 0.6 to $3 \mathrm{MW}$, scaling factors and empirical learning curves for the mass of single components as rotor, nacelle, tower and electronics were calculated and the following mathematical correlation was identified.

$$
\log y=\log a+b \times \log x
$$

Scaling factors $(b)$ and starting values $(\log a)$ are given in Table 3. Further details can be found in [31]. In order to apply this approach to determine material demand for WEC types not included in [31], the scaling factors had to be adapted. Therefore, a separate review of existing material data comprising each turbine type has been carried out to create type-specific scaling factors and starting values as shown in Table 4.

Table 3. Scaling factors and starting values applied for upscaling calculations; based on [31]. $M=$ Mass; $D=$ Rotor Diameter; Units: $D$ and $h$ in (m) and $M$ in $(\mathrm{kg})$.

\begin{tabular}{ccc}
\hline Scaling correlation & Scaling factor $\boldsymbol{b}$ & Starting value log $\boldsymbol{a}$ \\
\hline$M_{\text {rotor }}$ to $D$ & 2.22 & 0.3 \\
$M_{\text {nacelle }}$ to $D$ & 2.19 & 0.64 \\
$M_{\text {tower }}$ to $D^{2} h$ & 0.68 & 1.34 \\
$M_{\text {foundation }}$ to $D$ & 1.58 & 1.44 \\
\hline
\end{tabular}


Table 4. Adapted scaling factors and starting values. $M=$ Mass; $D=$ Rotor Diameter; Units: $D$ and $h$ in (m) and $M$ in (kg).

\begin{tabular}{ccccccc}
\hline \multirow{2}{*}{ Scaling correlation } & \multicolumn{2}{c}{ Onshore DFIG } & \multicolumn{2}{c}{ Onshore DDSG } & \multicolumn{2}{c}{ Onshore DDPMG } \\
\cline { 2 - 7 } & $\boldsymbol{b}$ & $\boldsymbol{a}$ & $\boldsymbol{b}$ & $\boldsymbol{a}$ & $\boldsymbol{b}$ & $\boldsymbol{a}$ \\
\hline$M_{\text {rotor }}$ to $D$ & 2.28 & 0.30 & 2.22 & 0.30 & 2.22 & 0.30 \\
$M_{\text {nacelle }}$ to $D$ & 2.19 & 0.64 & 2.20 & 0.9 & 2.19 & 0.64 \\
$M_{\text {tower }}$ to $D^{2} h$ & 1.82 & 1.70 & 1.82 & 1.6 & 1.82 & 1.7 \\
\hline
\end{tabular}

\subsubsection{Closing of Data Gaps}

For turbines where material data was not directly available, another modeling approach has been chosen. In general, the majority of wind turbine components are of identical specific material demand throughout the different types. Accordingly, a transfer of material demand data between different types can be considered a good enough approximation for most components except for drive train and foundation. Due to lack of data for DDPMG turbines, material data from other converter types had to be used. The majority of components such as rotor blades, tower, nacelle, etc. were taken from a DDSG turbine, as the general design is relatively close. Further, the drive train was modeled based on literature specializing on drive trains for wind turbines [13,28-30,32], and the material demand data were thus complemented. Likewise, the modeling of foundations for offshore turbines has been performed.

\subsubsection{Material Demand for Different WEC Types}

Following the approach described above, a table with material demand data for all turbine types mentioned in the classification was developed. Table 5 shows the results for all 18 turbine types plus an additional three turbine sizes for offshore converters.

\subsection{Analysis of Wind Energy Installations 1990-2010}

For the assessment of secondary material potentials, historic and future installations of wind energy converters have to be considered. Relevant installations of wind energy in Germany started in the 1990s. The underlying data has been taken from DEWI statistics [21,33]. These statistics include data on market shares of wind turbine manufacturers. Since companies stuck to a particular technology for at least several years, technology shares can be approximately deduced from market shares. The majority of producers used the DFIG concept up to 2010, while the leading manufacturer (Enercon) started to manufacture DDSG converters in 1993 and currently has a market share of about $60 \%$. Up to 2010, DDPMG can be considered as negligible for the German market.

In addition to the technology share, DEWI statistics provide data on the size development of wind turbines in the past. Based on this information, a complete allocation of installed WECs to the classes described in Section 2.2 could be performed. The results of this allocation are shown in Figure 4. 
Table 5. Material demand data for wind turbines ( $\mathrm{PM}=$ permanent magnets).

\begin{tabular}{cccccccc}
\hline \multirow{2}{*}{ Location } & \multirow{2}{*}{ Type } & \multirow{2}{*}{ Rated power $(\mathbf{M W})$} & \multicolumn{5}{c}{ Material amounts (t) } \\
\cline { 3 - 7 } & Concrete & Bulk metals & Plastics & Copper & PM \\
\hline \multirow{5}{*}{ Onshore } & DDPMG & 1.5 & 805.0 & 230.6 & 46.3 & 4.1 & 0.9 \\
& DDPMG & 2.5 & $1,218.1$ & 306.6 & 50.5 & 6.3 & 1.4 \\
& DDPMG & 3 & $1,930.5$ & 388.2 & 57.3 & 7.5 & 1.7 \\
& DDSG & 1.5 & $1,242.5$ & 213.6 & 34.6 & 7.2 & 0.0 \\
& DDSG & 2.3 & $1,880.0$ & 286.6 & 44.7 & 10.6 & 0.0 \\
& DDSG & 3 & $2,979.6$ & 448.3 & 75.2 & 15.2 & 0.0 \\
& DFIG & 1.65 & 805.0 & 235.4 & 45.5 & 3.7 & 0.0 \\
& DFIG & 2.3 & $1,218.1$ & 328.8 & 41.8 & 5.7 & 0.0 \\
& DFIG & 3 & $1,930.5$ & 418.7 & 52.3 & 7.0 & 0.0 \\
\hline DDPMG & 5 & 528.0 & $1,450.1$ & 108.8 & 12.2 & 2.8 \\
& DDPMG & 7 & 739.2 & $2,094.2$ & 194.1 & 17.6 & 4.0 \\
& DDPMG & 12 & 0.0 & $1,357.7$ & 153.1 & 18.8 & 6.8 \\
DDPMG & 24 & 0.0 & $10,198.2$ & 400.1 & 37.7 & 13.6 \\
& DDSG & 5 & 528.0 & $1,461.5$ & 59.2 & 27.8 & 0.0 \\
& DDSG & 7 & 739.2 & $2,108.5$ & 112.2 & 39.5 & 0.0 \\
& DDSG & 12 & 0.0 & $1,338.8$ & 138.8 & 59.0 & 0.0 \\
& DDSG & 24 & 0.0 & $10,172.2$ & 360.3 & 117.5 & 0.0 \\
& DFIG & 5 & 528.0 & $1,458.8$ & 76.9 & 12.6 & 0.0 \\
& DFIG & 7 & 739.2 & $2,212.4$ & 143.2 & 21.4 & 0.0 \\
DFIG & 12 & 0.0 & $1,441.2$ & 112.5 & 10.7 & 0.0 \\
DFIG & 24 & 0.0 & $10,397.8$ & 767.5 & 25.6 & 0.0 \\
\hline
\end{tabular}

Figure 4. Annual Onshore WEC installations by turbine type and size in Germany.

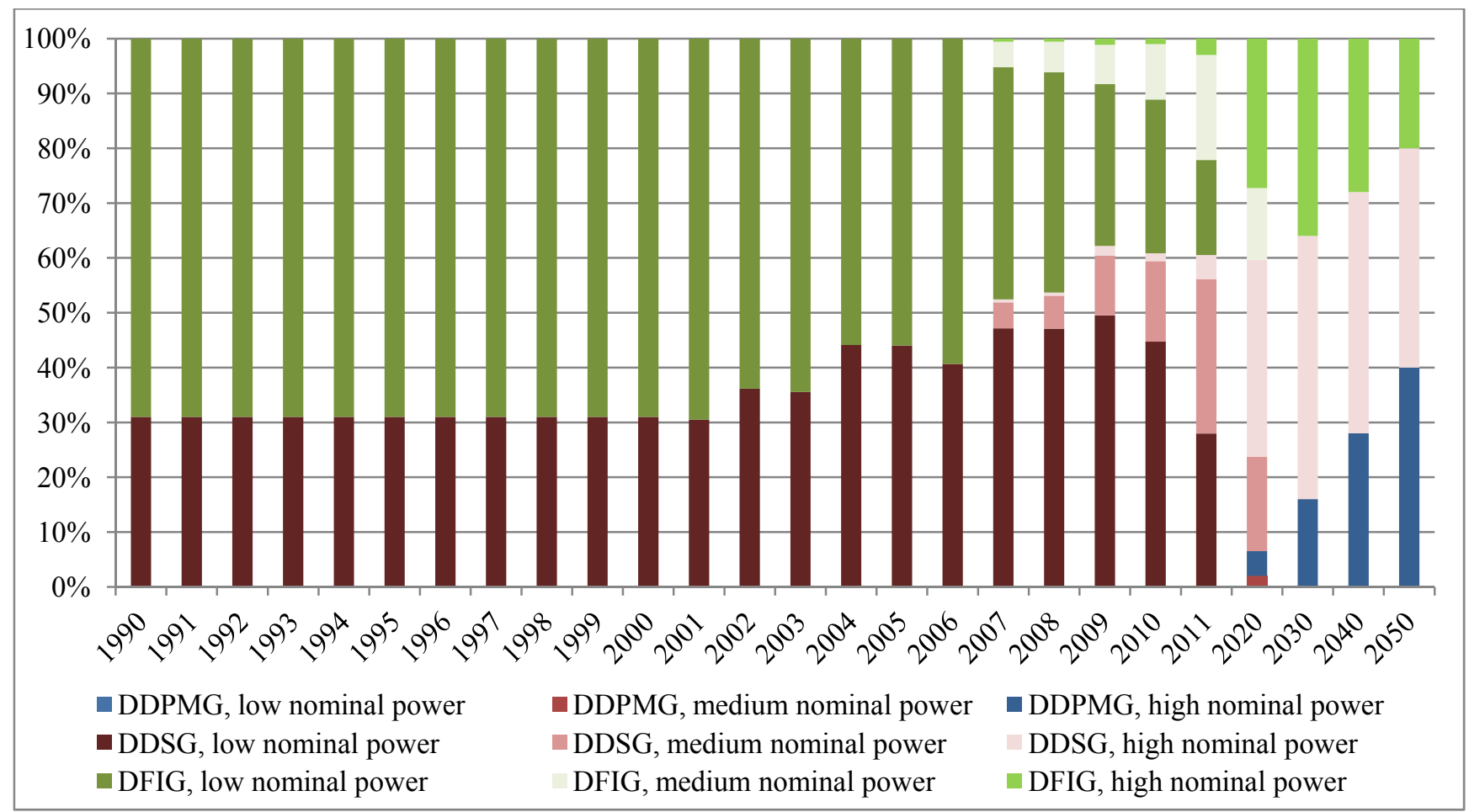


The total installations in Germany from 1990 to 2010 are shown in Figure 5. The all-time peak of new installations was in 2002, when a total of 3240 MW of wind power was installed. In 2010, total installed capacity rose to more than 27,000 MW. These figures are taken from annual reports published by the German wind energy institute (DEWI) GmbH [21].

Figure 5. Annual installations and cumulative nominal power for the years 1990-2010 in Germany [21].

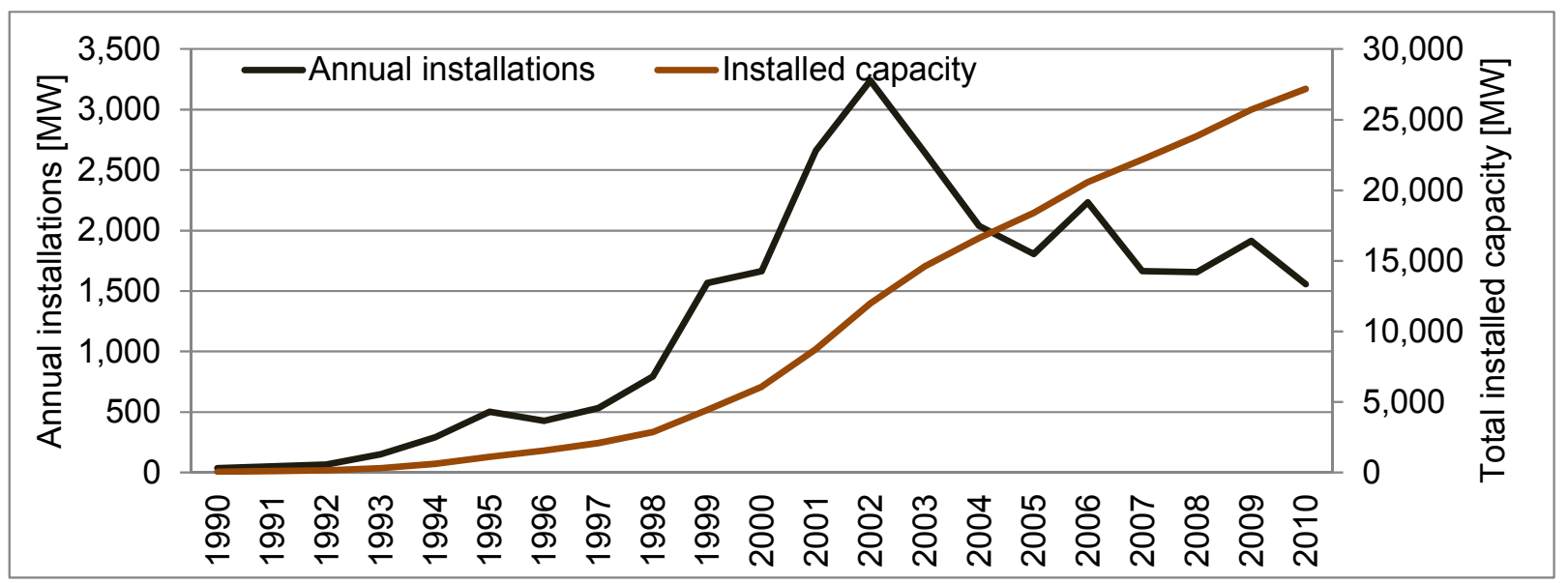

\subsection{Assumptions about Future Development}

Regarding future installations of wind turbines, different publicly available scenarios have been assessed. Four scenarios have been chosen for further analyses. The scenario 2011A (short: 2011A) from the "Leitstudie 2011" of the German Ministry for the Environment (BMU) [4] has been chosen as a reference scenario. It was chosen as a reference, since it is the most recent scenario including also relevant post-Fukushima policy changes in Germany. Further assumptions in this scenario include a decline of population to 73.5 million in 2050; a rising energy demand and a $38.8 \%$ increase of the GDP by 2050. Other scenarios used are the scenario IV (short: IV) from a study of the German Ministry of Economics and Technology (BMWi) assuming a prolonged use of nuclear power and thus a less intensive growth of renewables [34]. In the third scenario an increased use of carbon-capture-and-storage technology (short: CCS) from 2020 on is assumed. This scenario was taken from a WWF study [35]. Additionally, a "100\% renewables until 2050" scenario was taken from a 2010 study of the German Ministry for the Environment (short: 100\%). In this scenario a share of $66 \%$ e-mobility by 2050 and full coverage of energy demand by renewables is assumed [36]. A comparison of these scenarios in terms of total and annually installed capacity is shown in Figure 6.

Concerning the future development of turbine technology and size until 2050, further assumptions had to be made based either on studies about future technological development or expert opinions.

Today, the largest onshore turbines (such as the Enercon E-126) reach enormous sizes, with rotor diameters of up to $126 \mathrm{~m}$. Yet, these very large turbines will probably remain exceptions in the future, especially since onshore transport is a serious problem. German highway bridges and other obstacles limit the maximal transportation diameter to around $4.5 \mathrm{~m}$ which leads to a projected average turbine size that stabilizes at around 3 to $4 \mathrm{MW}$ with a diameter of about $100 \mathrm{~m}$ [37-39]. 
Figure 6. Comparison of installed wind energy capacity in different energy scenarios. (a) Annual installations; and (b) total installations.

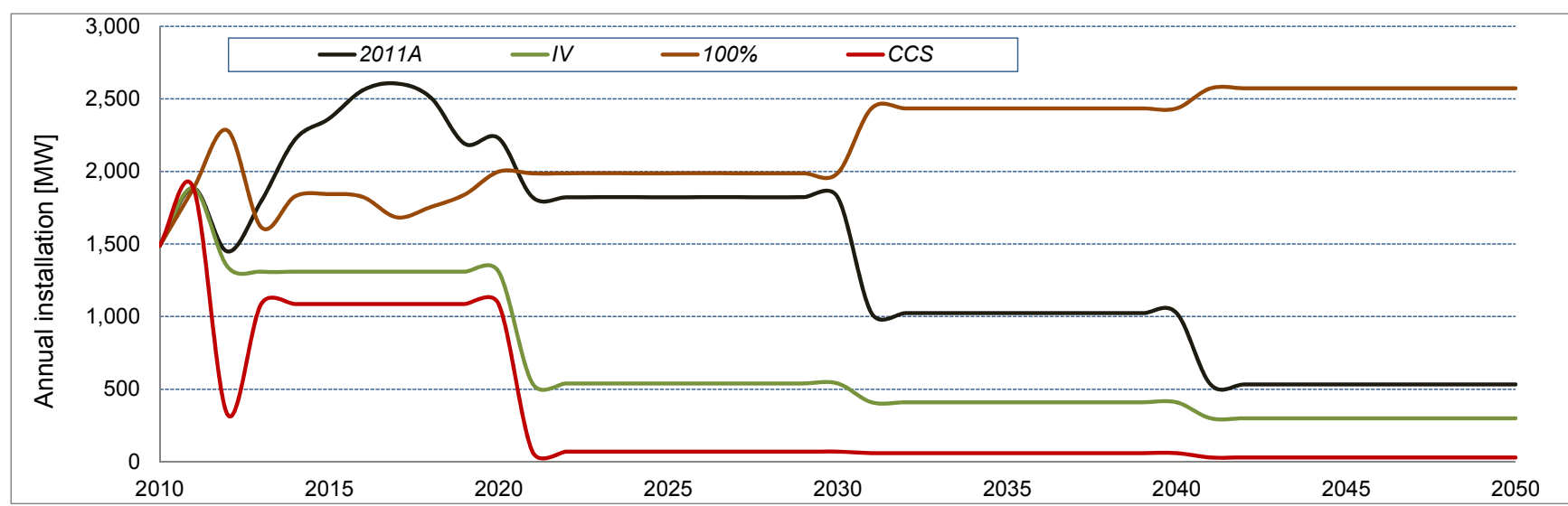

(a)

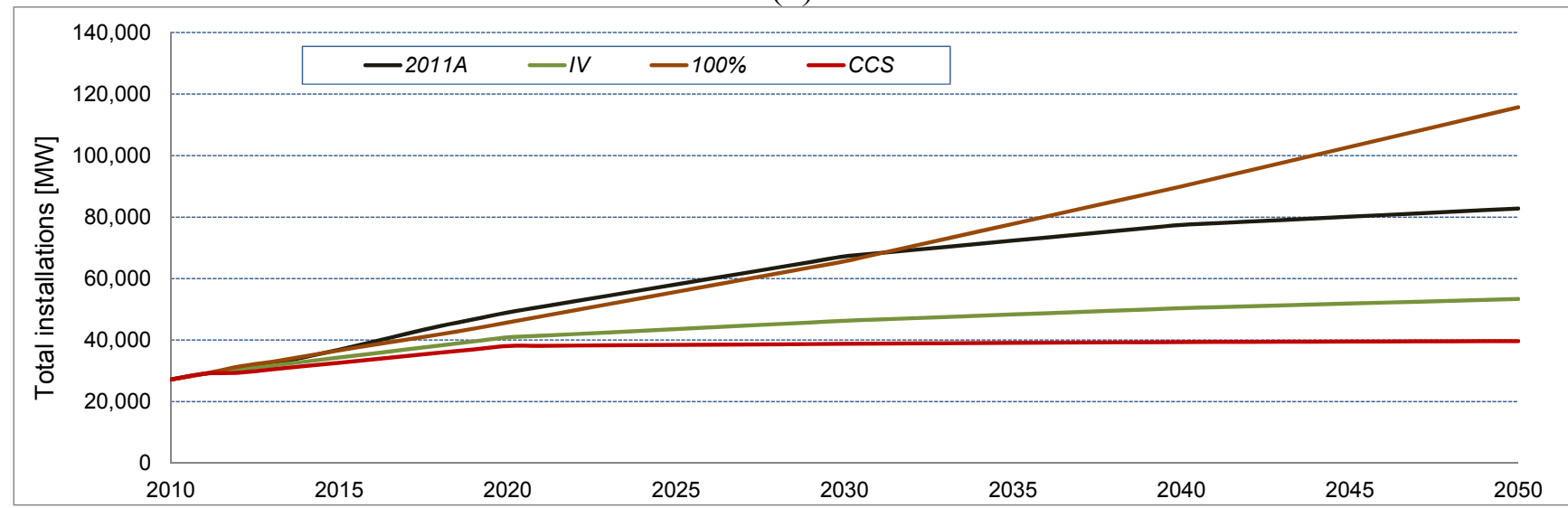

(b)

As a major data source for offshore WEC development, results from the "NEEDS Project" served as a base for all technological and size developments [16]. In this study, an average turbine size of 12 MW until 2025 and 24 MW by 2050 is predicted. These values are in accordance with other studies analyzing the feasibility of large turbines such as the "UpWind Project" and other publications [40,41].

For the development of the drive train shares, tower design and foundation design until 2050, assumptions have been made based on the literature [37,42]. Different drive trains will be applied in both onshore and offshore turbines in the future as no drive train design has turned out to clearly outmatch the others. Changing shares of drive train principles are basically caused by trends towards new technologies such as DDPMG [42]. In offshore turbines more and more gearless converters will be used, as there is an advantage through lower maintenance costs [37]. Foundations for onshore turbines are assumed not to be affected by any significant future changes as alternatives to regular concrete flat foundations are seldom applied due to higher costs. However, in regions with moist and unstable ground conditions, pile foundations are used, which is not taken into account in this study, as hardly any material demand data could be obtained. Offshore, however, diverse foundation types will be applied, all consisting of steel constructions. The design is assumed to be shifting from current jacket and tripod foundations towards a majority of tripod foundations. Monopiles are regarded as a short-term phenomenon [16]. A summary of the described assumptions is given in Table 6 . 
Table 6. Main assumptions for future technological development of WEC installed in Germany.

\begin{tabular}{ccccccccc}
\hline Component & & \multicolumn{3}{c}{ Onshore WEC } & \multicolumn{3}{c}{ Offshore WEC } \\
\hline & Year & $\mathbf{2 0 1 0}$ & $\mathbf{2 0 2 5}$ & $\mathbf{2 0 5 0}$ & $\mathbf{2 0 1 0}$ & $\mathbf{2 0 2 5}$ & $\mathbf{2 0 5 0}$ \\
\hline \multirow{3}{*}{ Drive train (shares in \%) } & DFIG & 41 & 40 & 20 & 100 & 80 & 10 \\
& DDSG & 59 & 50 & 40 & 0 & 10 & 40 \\
& DDPMG & 0 & 10 & 40 & 0 & 10 & 50 \\
\hline & Flat foundation & 100 & 100 & 100 & 0 & 0 & 0 \\
Foundation (shares in \%) & Monopile & 0 & 0 & 0 & 0 & 20 & 0 \\
& Tripod & 0 & 0 & 0 & 50 & 40 & 70 \\
& Jacket & 0 & 0 & 0 & 50 & 40 & 30 \\
\hline \multirow{2}{*}{ Tower design (shares in \%) } & Tubular steel & 90 & 80 & 60 & 100 & 90 & 80 \\
& Concrete & 10 & 20 & 40 & 0 & 10 & 20 \\
\hline Hub height & Average (m) & 99 & 120 & 130 & 90 & 130 & 150 \\
\hline Rotor diameter & Average (m) & 80 & 100 & 100 & 120 & 160 & 250 \\
\hline Nominal Power & Average (MW) & 2.0 & 3.0 & 3.6 & 5 & 12 & 24 \\
\hline
\end{tabular}

\subsection{Application of the Weibull Function for Modeling Material Demand Lifespan Distribution}

The converters lifespan and discard patterns, respectively, are modeled using the Weibull function. The Weibull distribution has been found to give a good approximation of product lifespans and is commonly used to model discard patterns (see for example [43-48]). Still, many studies assessing anthropogenic material flows and product service lives assume (often implicitly) a simultaneous exit function for the products' end-of-life [49]. In these cases, it is usually assumed that all products entering the use phase in year $X$ are simultaneously discarded in year $X+\bar{T}$, with $\bar{T}$ being the average product lifespan. For wind energy converters this has, for example, been done in [50], other examples are given in [49]. It has been noted, though, that the simultaneous exit function is the most inappropriate function to approximate product lifespans ( $c f$. [49,51]).

The Weibull probability density function can be defined as:

$$
f(t, \lambda, k)=\lambda k(\lambda t)^{k-1} e^{-(\lambda t)^{k}}
$$

with $t$ being the time in years (the lifespan) while $k$ and $\lambda$ are the shape and scale parameters determining scale and shape of the distribution curve.

The average product lifespan $\bar{T}$ depends on both, the scale parameter $\lambda$ and the shape parameter $k$. It is given by the 1 st moment of the Weibull distribution $\bar{T}=\frac{1}{\lambda} \Gamma\left(1+\frac{1}{k}\right)$. According to [43] the following general statements on the risk of discard (end of life) can be made regarding the shape parameter $k$ :

- $\quad 0<k<1 \quad \rightarrow$ risk of discard decreases over time;

- $k=1 \quad \rightarrow$ risk of discard remains constant over time;

- $\quad 1<k<2 \quad \rightarrow$ risk of discard increases with age but at a decreasing rate;

- $k=2 \quad \rightarrow$ risk of discard increases linearly;

- $k>2 \quad \rightarrow$ risk of discard increases progressively.

In the literature, $k$ values between 1 and 3 are reported (e.g., [43,46,49,52]) for different kinds of products. To the authors' knowledge, studies explicitly dealing with wind turbines have not yet been 
published, but based on the values reported for other products a $k$-value of 2 is assumed here. This value is in the range of various long living infrastructures or industrial commodities like office buildings $(k=1.81)$, other non-residential buildings $(k=1.8)$, electric power plants $(k=1.73)$, trucks ( $k=2.2$ to 3$)$, and industrial robots $(k=2.45)$ [52]. The influence of different $k$-values on the results is highlighted in the discussion section.

In many studies, the average converter lifespan is assumed to be 20 years (see for example [13,14,53]). In the Weibull distribution, the characteristic lifespan $T$, which is the inverse of the scale parameter $\lambda$, represents the time span after which $63.2 \%$ of the products have been discarded. Using the relation given above, $T$ and $\lambda$ can be calculated based on the average lifespan and the shape parameter $k$. For the given values of $\bar{T}=20$ and $k=2$ the characteristic lifespan $T$ is 22.568 and accordingly $\lambda=0.0443$.

\subsubsection{Modeling the Converter End-of-Life and Secondary Material Flows}

For converters installed at time $t$, the fraction being discarded at time $t+i$ is calculated using the Weibull function as:

$$
f(i, \lambda, k)=\lambda k(\lambda i)^{k-1} e^{-(\lambda i)^{k}}
$$

For calculating the discarded amounts for a full year in the future, we have to consider all the converters being installed in year $X$ (i.e., we have to integrate $t$ over a full year) and consider the corresponding lifespans from $(i-1)$ to $i$. It is safe to assume, that the installation rate is constant across a particular year, and we denote this rate by $\dot{C}$. With these assumptions and the above equation, the total capacity of converters being discarded in year $X+i$ (denoted as $C_{d}(X+I)$ can be calculated as:

$$
C_{D}(X+i)=\dot{C} \int_{i-1}^{i} f(t, \lambda, k) d t
$$

\subsubsection{Material Demand for Replacement, New Installations and Total Material Demand}

As described in Section 2.5, none of the included energy scenarios assumes a reduction of the installed wind energy capacity over time. Given this, it can be assumed that converters reaching their end-of-life are replaced by new converters with a higher capacity and different technological characteristics due to the changes described in Section 2.5. Of course, new converters will in fact have a much higher power rating than replaced converters. Accordingly, in the model calculation this growth in installed capacity is treated as new installations. The material demand from new installations is then calculated based on the newly installed capacity and the different technology shares as well as the distribution between onshore and offshore locations in the respective year. The total material demand is the sum of the material demand of converter replacements and material demand from new installations.

\subsection{MIPS Concept}

The MIPS concept (material input per service unit) quantifies the life-cycle-wide input of materials required for a product or service unit. The MIPS value is calculated as the mass of resources taken from or moved within the environment. These resource uses and movements are differentiated into five 
categories: biotic or renewable raw material, abiotic or non-renewable raw material, water, air, and earth movement in agriculture and silviculture (incl. erosion) [54]. The sum of biotic and abiotic material input plus earth movements is called Total Material Requirement (TMR). The concept, thus, aims at estimating the input oriented impacts on the environment caused by the manufacture of products and services (see e.g., p. 9 in [54]). Being an input oriented indicator, limitations to its ability to capture environmental impacts have to be noted. The most obvious limitation is the fact, that emissions based environmental impacts, such as eco-toxicity, are not covered by the MIPS concept. The MIPS concept also does not distinguish between scarce and non-scarce materials. The strength of the MIPS concept clearly lies in the fact that it is easy to grasp, thus reduces complexity and gives a concise account of environmentally relevant inputs to products and services. In a narrow sense, the amount of materials extracted from the environment is not a direct indicator of their environmental relevance. However, extraction and movement of materials in the environment is always linked to environmental impacts, and the more is extracted, the higher this impact. The extracted amount of materials can thus serve as a proxy for environmental disturbances or as a generic indicator for the stress a system exerts on the environment ( $c f$. [55]). It has to be noted that MIPS is a rather crude proxy and it should not be used alone when evaluating technologies. In the context of this analysis it adds generic information on the environmental stress accompanying the growth of wind energy in Germany.

With the help of the MIPS concept, the total input of material resources for building and maintaining the large scale infrastructure of wind energy can be calculated. In order to do so, MI-values from [56] have been used and results for three categories - abiotic material, water, and air - have been calculated. Factors for biotic materials and earth movements were not available.

In order to be able to apply the MIPS concept, a couple of assumptions and simplifications had to be made. The direct material demand connected with wind energy expansion was calculated on a rather aggregated level (i.e., materials have been aggregated into material groups). These material groups had to be disaggregated again in order to allow applying the MIPS concept. However, an overly detailed disaggregation, e.g., a disaggregation into different steel types, would not be consistent with the aggregation of converters of different types and producers into the categories described above (see Section 2.2).

The group of bulk metals as used in the material bill of the different wind energy turbine types consists mainly of iron, steel, and aluminum. The aluminum share within this category amounts to about two percent of the total material flows. Accordingly, iron and steel amount to about $98 \%$, while other materials within this group are considered negligible. A differentiation between iron and steel or different steel types is not made. Copper and concrete, however, have been assessed separately.

The MI values for copper, aluminum and steel are dependent on the ratio of primary to secondary metals production. For aluminum and copper, average ratios have been used (as given in [56]). For steel the ratio has been derived from current recycling input rates for steel making and the MI value has been calculated correspondingly.

Disaggregating the materials group of plastics is not straight forward. Based on the material balances and data from the underlying studies (e.g., [11-13]) a share of 50\% is assumed for glass fiber reinforced plastics, containing mainly glass fiber and epoxy resin. For the other $50 \%$ a mix of different plastics is assumed. Due to the relatively small share of plastics in the total material demand, the potential error resulting from this approximation can be considered negligible. 
MI-values for rare earths used in permanent magnets have not been available, so we had to find a proxy material. We have chosen silver as a proxy material based on the following arguments. In [57] the correlation between various aggregated environmental impact indicators and cumulative energy demand (CED) has been explored. Quite generally, the correlation is strong ( $R^{2}$ between 0.61 and 0.81 ), especially for metals. MIPS as an indicator was not part of the correlation analysis, but the strong correlation between CED and all the other aggregated indicators leads us to believe that the correlation is also valid for MIPS. This reasoning is based on the fact that also all the other indicators are some form of weighted aggregation of material flows, as is the MIPS indicator, albeit that for MIPS only material input is summed, but not output. The CED values for rare earth oxides vary between 22 and $1100 \mathrm{MJ} / \mathrm{kg}$ [58], depending on the specific rare earths involved. For neodymium oxide the value is $761 \mathrm{MJ} / \mathrm{kg}$, when $\mathrm{Nd}$ is won from a mix of rare earth oxides in a combined metallurgical process. The CED for silver is $1480 \mathrm{MJ} / \mathrm{kg}$ (global average production), which is close in comparison with other metals. By using silver as a proxy for the rare earth elements (especially neodymium), we thus probably overestimate the corresponding material input for rare earths. However, the relative amount of rare earths in wind energy converters is small, and thus the error seems acceptable. A discussion of the potential error introduced by this approximation can be found below (Section 3.4). In addition to finding a proxy for rare earths, the permanent magnet material had to be differentiated into different materials. A composition of $68 \%$ iron (with steel as proxy) and $31 \%$ rare earths (with silver as proxy) was assumed. With these approximations and assumptions we were then able to complete the MIPS calculation.

The breakdown of the material groups into materials and the applied MI-values are shown in Table 7. It has to be noted that no change of these values over time is considered in the assessment.

Table 7. Breakdown of material groups into materials and applied material intensity values.

\begin{tabular}{|c|c|c|c|c|c|c|c|c|c|c|}
\hline \multirow{2}{*}{\multicolumn{2}{|c|}{$\begin{array}{l}\text { Material group } \\
\text { Materials }\end{array}$}} & \multirow{2}{*}{$\frac{\text { Concrete }}{\text { Concrete }}$} & \multicolumn{2}{|c|}{ Bulk metals } & \multirow{2}{*}{$\frac{\text { Copper }}{\text { Copper }}$} & \multicolumn{2}{|c|}{ PM } & \multicolumn{3}{|c|}{ Plastics } \\
\hline & & & $\begin{array}{l}\text { Iron, } \\
\text { Steel }\end{array}$ & Aluminum & & Iron & $\begin{array}{c}\text { Rare } \\
\text { earths }\end{array}$ & $\begin{array}{l}\text { Glass } \\
\text { fibre }\end{array}$ & $\begin{array}{c}\text { Epoxy } \\
\text { resin } \\
\end{array}$ & $\begin{array}{c}\text { Other } \\
\text { plastics }\end{array}$ \\
\hline material & group & $100 \%$ & $98 \%$ & $2 \%$ & $100 \%$ & $70 \%$ & $30 \%$ & $38 \%$ & $13 \%$ & $50 \%$ \\
\hline \multirow{4}{*}{$\begin{array}{l}\text { Material intensity } \\
(\mathrm{kg} / \mathrm{kg})\end{array}$} & abiotic material & 1.33 & 8 & 18.98 & 179.07 & 8 & 7500 & 10.84 & 13.73 & 2.5 \\
\hline & biotic material & 0 & 0 & 0 & 0 & 0 & 0 & 0 & 0 & 0 \\
\hline & water & 3.42 & 60 & 539.21 & 236.39 & 60 & 0 & 296.25 & 289.88 & 150 \\
\hline & air & 0.04 & 0.5 & 5.91 & 1.16 & 0.5 & 0 & 2.01 & 5.5 & 2.5 \\
\hline
\end{tabular}

\section{Results}

Following the approach described above the resulting material flows - direct material demand and secondary flows - have been calculated. At first, the results for the reference scenario (Leitstudie 2011A in [4]) are presented. Afterwards, the results for other assessed scenarios are presented and compared.

\subsection{Results for the Reference Scenario}

In the reference scenario the aggregated direct material demand (all material groups aggregated) shows a rather steady growth up to 2050 with slight peaks occurring in 2016, 2020, 2030, and 2040. 
This demand grows from $2244 \mathrm{kt}$ in 2020 to $3284 \mathrm{kt}$ in 2050 . Within the direct material demand, concrete accounts for about $70 \%$ in 2020 and 2030, but decreases due to the increased installation of offshore converters to about $65 \%$ in 2050 . The share of bulk metals increases correspondingly from about $25 \%$ in 2020 to $32 \%$ in 2050 . A more than sevenfold increase from 2020 to 2050 can be observed for permanent magnet material resulting from the increased use of DDPMG converters. An overview of the direct material demand in 2020, 2030, 2040, and 2050 is given in Table 8.

Table 8. Direct material demand for selected year in reference scenario (kt).

\begin{tabular}{ccccccc}
\hline Year & Concrete & Bulk metals (iron, steel, aluminum) & Plastics & Copper & Permanent magnets & Total \\
\hline 2010 & 1010 & 230 & 34 & 6 & - & 1281 \\
2020 & 1603 & 569 & 60 & 11 & 0.14 & 2244 \\
2030 & 2030 & 745 & 74 & 12 & 0.40 & 2863 \\
2040 & 2144 & 886 & 82 & 13 & 0.72 & 3131 \\
2050 & 2121 & 1059 & 80 & 13 & 1.04 & 3284 \\
\hline
\end{tabular}

While the direct material demand shows a rather continuous growth, the additionally installed capacity per year does not grow likewise (see Figure 6). This opposed development is caused by the growing share of material demand for turbine replacement. Figure 7 shows the development of material demand arising from new installations and converter replacement. It can be seen that already in 2019 converter replacement shows a higher material demand than new installations.

Figure 7. Direct material demand from new installations and replacement (for scenario 2011A in [4]).

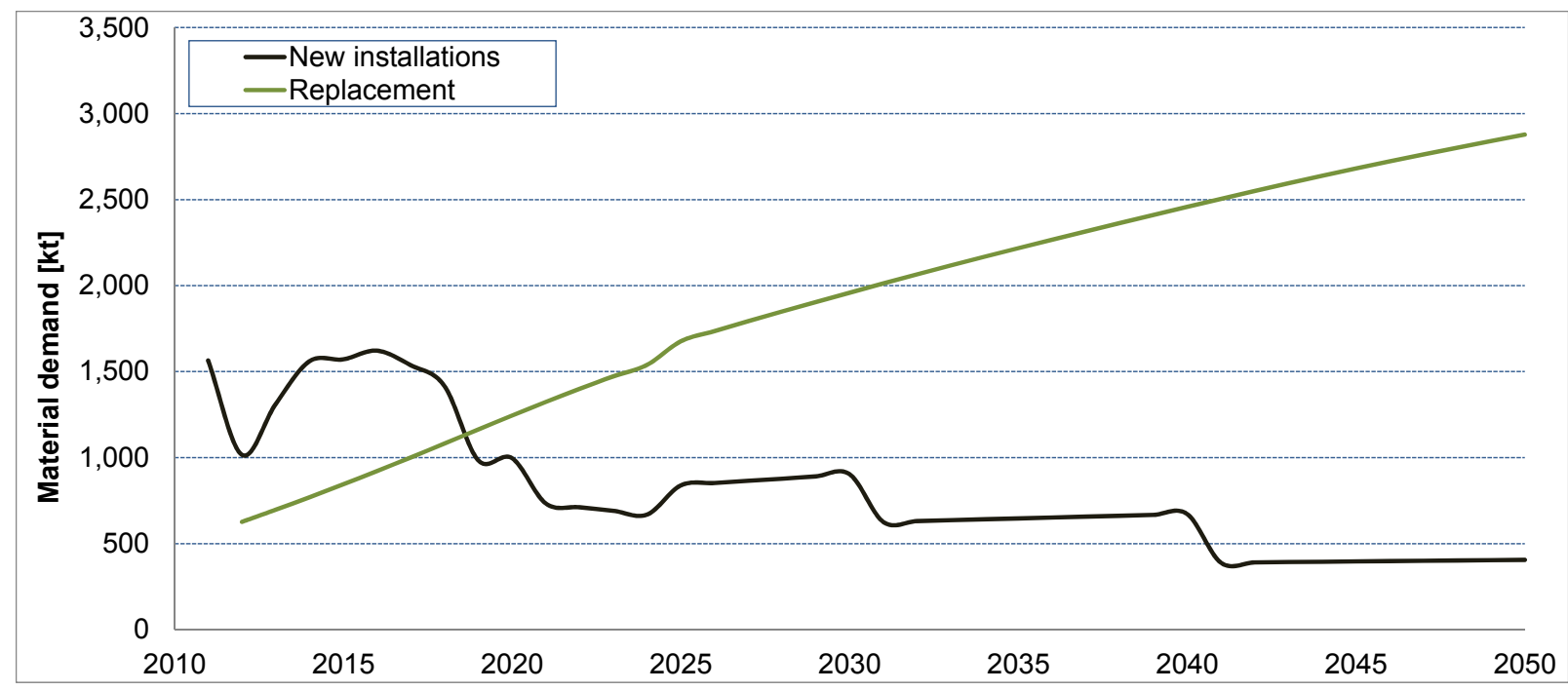

With the direct material demand growing steadily up to 2050, the secondary material potential grows likewise. The total flows of secondary material as well as flows in the different material groups are shown in Figure 8. Concrete represents by far the largest flow in terms of mass, followed by bulk metals (iron, steel, aluminum). A closer look at plastics, copper, and permanent magnet material is shown in Figure 9. Although the flow of secondary permanent magnet material is - in terms of mass- relatively low in comparison to the other materials, it is of great significance due to the material's criticality. The typical composition of $\mathrm{NdFeB}$ permanent magnets used in wind energy converters is 
$68 \%$ of iron, $29 \%$ of neodymium, $2 \%$ dysprosium, and $1 \%$ boron [59]. This composition has been assumed to remain constant over time. The world production of neodymium and dysprosium in 2010 was around $21 \mathrm{kt}$ and $1.2 \mathrm{kt}$, respectively [60] with more than $97 \%$ being produced in China. Against this background, the growing secondary material flows (permanent magnets) of $6.1 \mathrm{t}$ in 2020 (1.8 $\mathrm{t}$ of $\mathrm{Nd}, 0.12 \mathrm{t}$ of Dy), $45.8 \mathrm{t}$ in 2030 (13.3 t of Nd, $0.9 \mathrm{t}$ of Dy), $160 \mathrm{t}$ in 2040 (46.4 t of Nd, $3.2 \mathrm{t}$ of Dy) and $369 \mathrm{t}$ in 2050 (107 t of $\mathrm{Nd}$ and $7.4 \mathrm{t}$ of Dy) appear much more significant.

Figure 8. Secondary material flows from dismantled turbines in reference scenario.

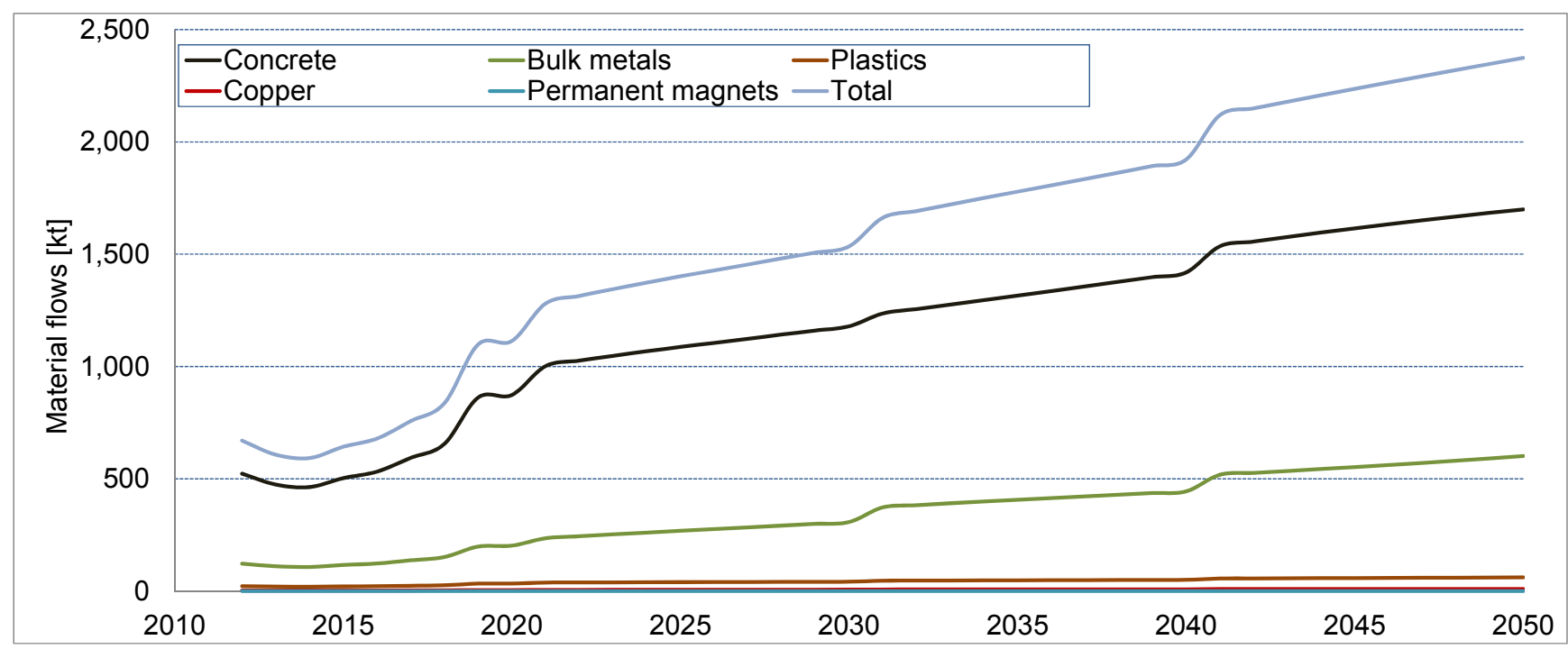

Figure 9. Secondary material flows of plastics, copper and permanent magnets in reference scenario; permanent magnet flows are shown on the secondary $y$-axis.

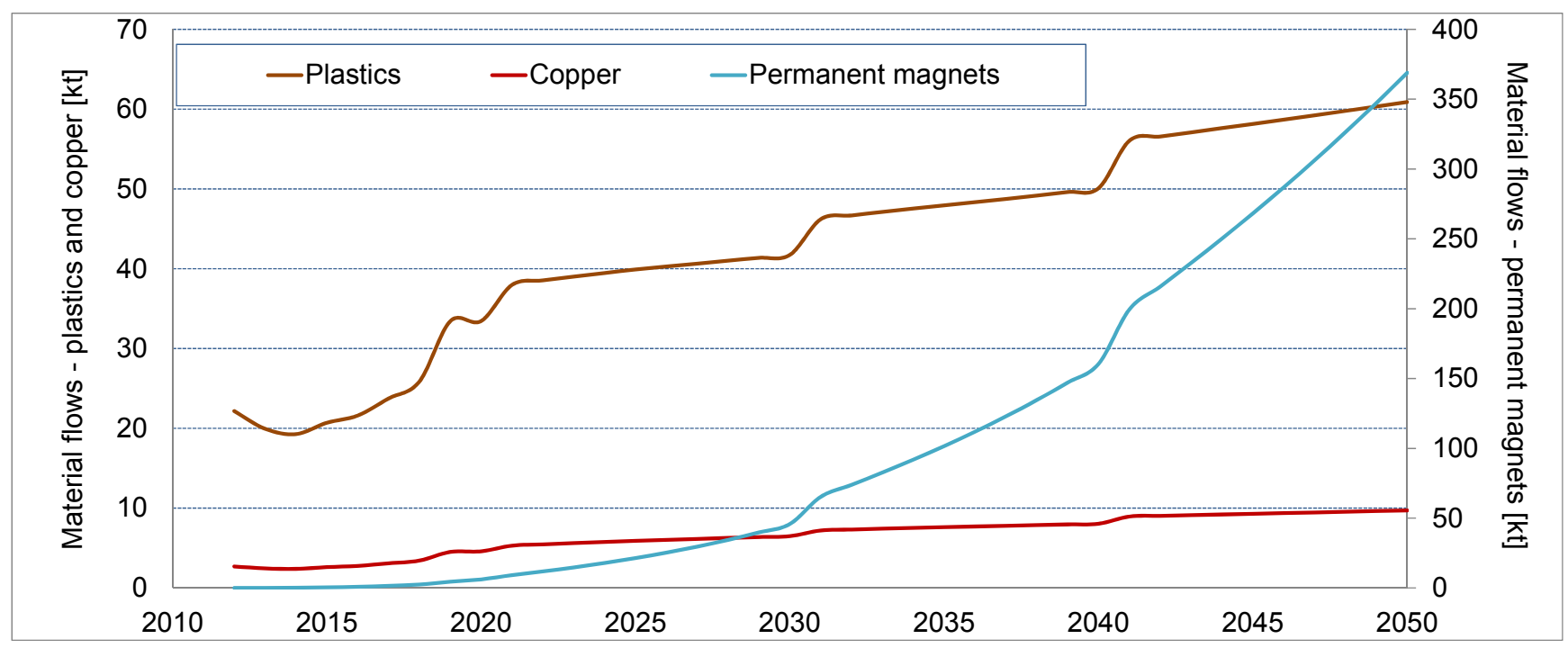

To highlight the potential of efficiently utilizing the flows of secondary material, the development of material demand and secondary material potential needs to be looked at together. If the secondary material flows are subtracted from the material demand a theoretical net material demand can be calculated (see Figure 10). This gives an idea of the potential for resource conservation which an efficient recycling infrastructure for wind turbines might bring along. The net material demand 
calculated in this way is, however, a rather theoretical figure and recycling rates need to be applied to get a more realistic picture. An overview of current recycling rates for materials from wind energy converters is presented in Table 9. For metals like iron, steel, and aluminum recycling rates of at least $80 \%$ are commonly assumed. Copper shows even higher recycling rates of over $90 \%$. For plastics and concrete, recycling remains a challenge. The relatively high recycling rates of above $90 \%$ for these materials given in Table 9 are misleading. Currently, rotor blades are usually incinerated with energy recovery, while concrete is downcycled and used, for example, as filling material. Therefore, secondary material flows of concrete and plastics cannot currently being used as substitute for primary material in wind turbine production.

Table 9. Recycling rates and procedures for dismantled WEC [13,61-64].

\begin{tabular}{ccc}
\hline Material group & Recycling rate & Secondary use and processing \\
\hline Concrete & $91 \% *$ & Fill material \\
Bulk metals & $80 \%$ & Melting processes and refining (with quality losses) \\
Plastics & $95 \% *$ & Pyrolysis, burning and use as an addition to cement \\
Copper & $95 \%$ & Melting processes and refining (no quality losses) \\
Rare Earths & $0 \%$ & Dry extraction \\
\hline
\end{tabular}

Note: * energy recovery or downcycling is considered as recycling.

Figure 10. Material flows and (theoretical) net material demand for reference scenario.

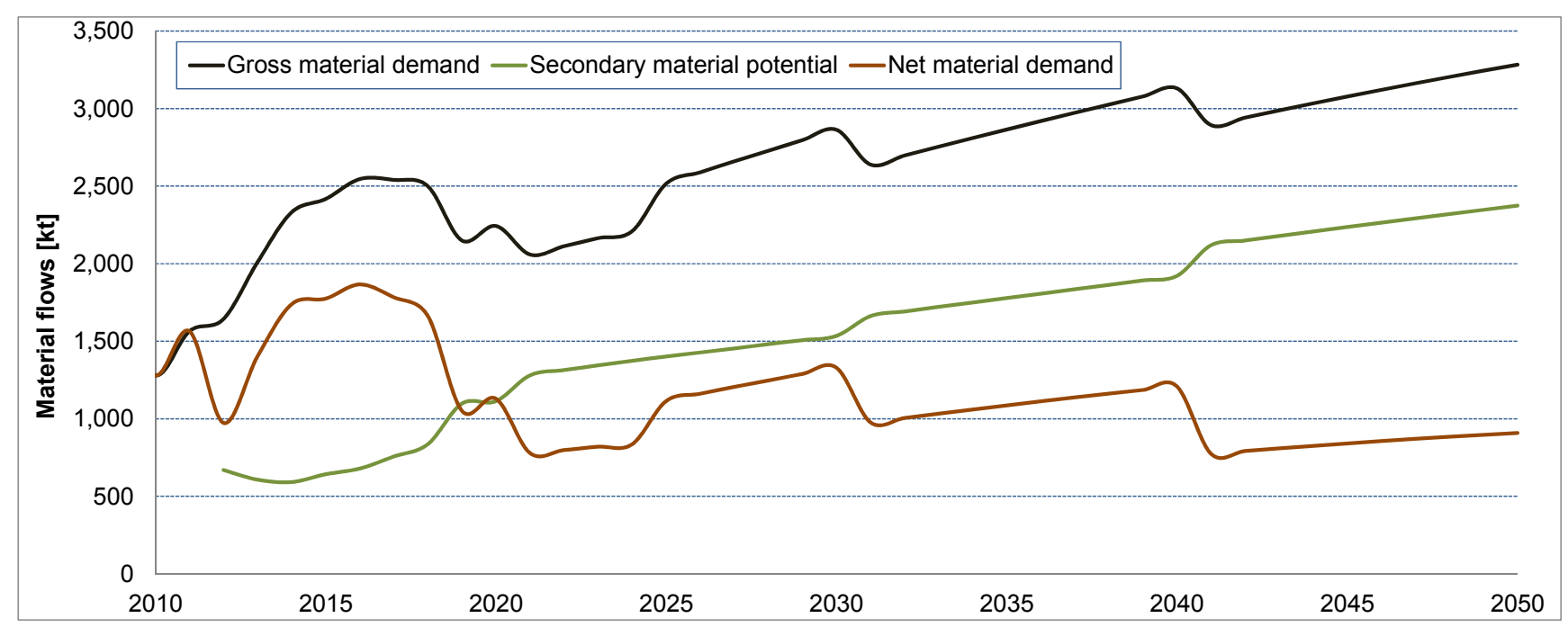

\subsection{Scenario Comparison}

Since the compared scenarios differ in their assumptions about the development of the installed capacity, they also differ in the resulting material demand. The development of the total material demand in the different scenarios is shown in Figure 11.

Among the different scenarios, the $100 \%$ renewables scenario shows the highest material demand on the long run while the CCS scenario is positioned at the very bottom. Up to 2030, the reference scenario - 2011 A - which is based on the most recent energy study, has a material demand even higher but very close to the $100 \%$ renewable scenario. After 2031 the material demand of the $2011 \mathrm{~A}$ scenario is lower but still higher than in the other two scenarios (IV and CCS). 
Figure 11. Sum of direct material demand in different scenarios.

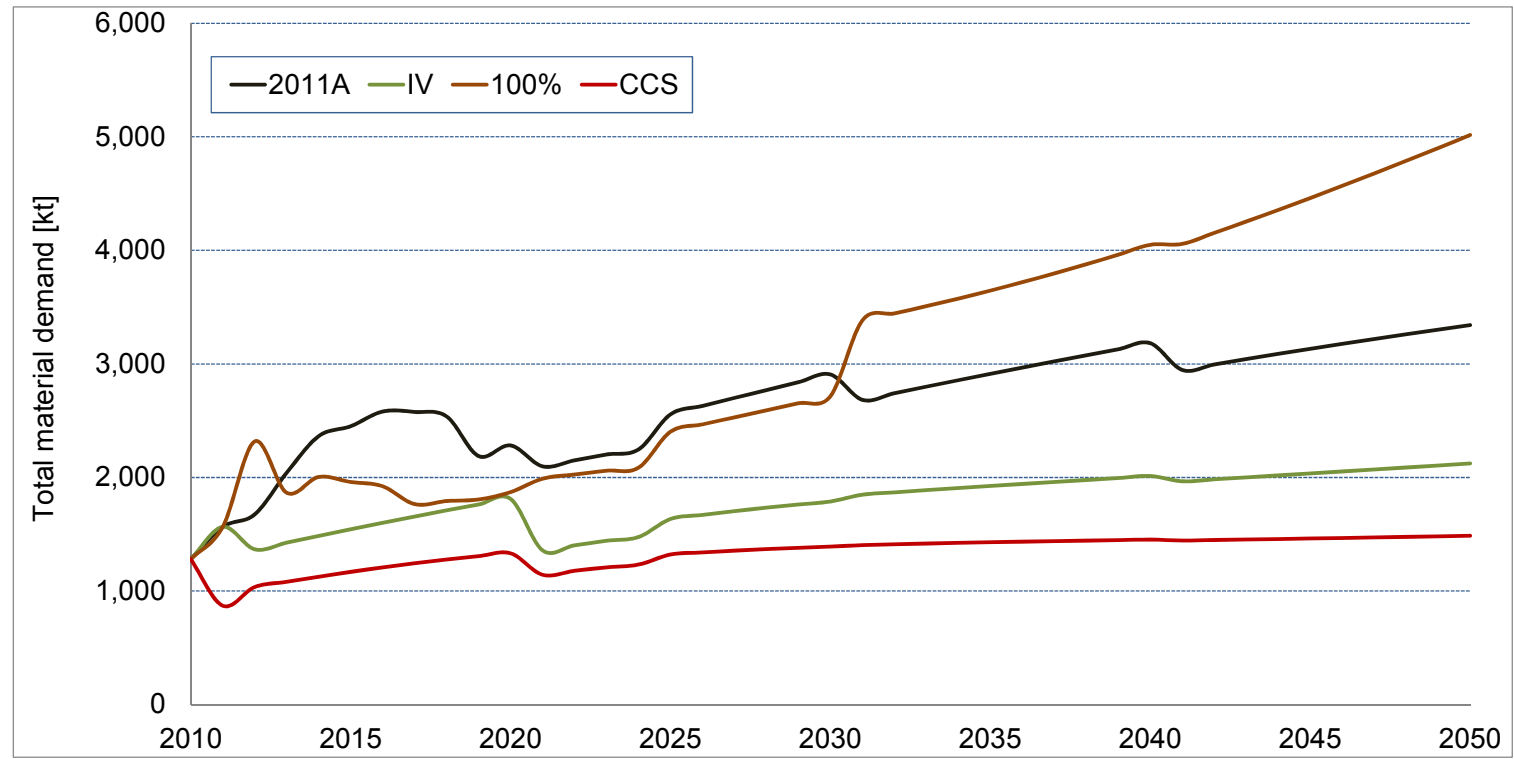

Figure 12 shows a breakdown into the different material groups for all scenarios. Concrete and plastics demand shows a similar trend as the aggregated material demand in Figure 11. Similar to that is the trend of copper demand. Still, it has to be noted that in scenarios "IV" and "CCS" concrete, copper and plastic demand remain rather constant from 2030 on. On the other hand, bulk metals, mainly steel, show a continuous growth due to the increasing number of offshore installations (e.g., tripods of currently installed offshore WEC have a steel demand of at least $845 \mathrm{t}$ each [65]).

Figure 12. Material demand for material groups in different expansion scenarios until 2050. (a) Concrete; (b) bulk metals; (c) plastic; (d) copper; and (e) permanent magnets.

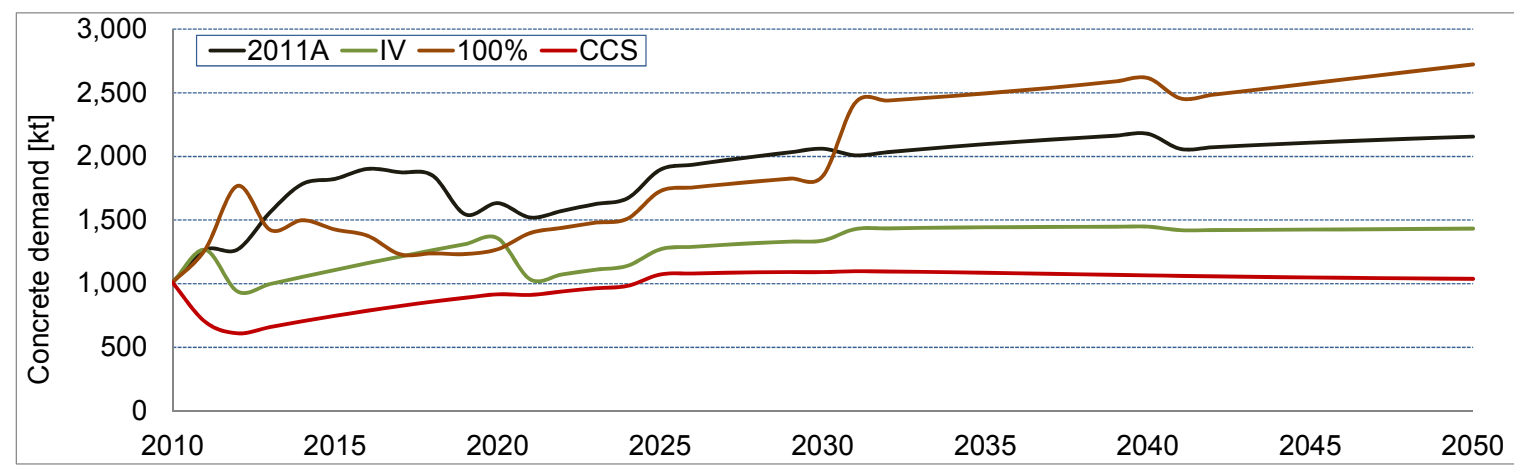

(a)

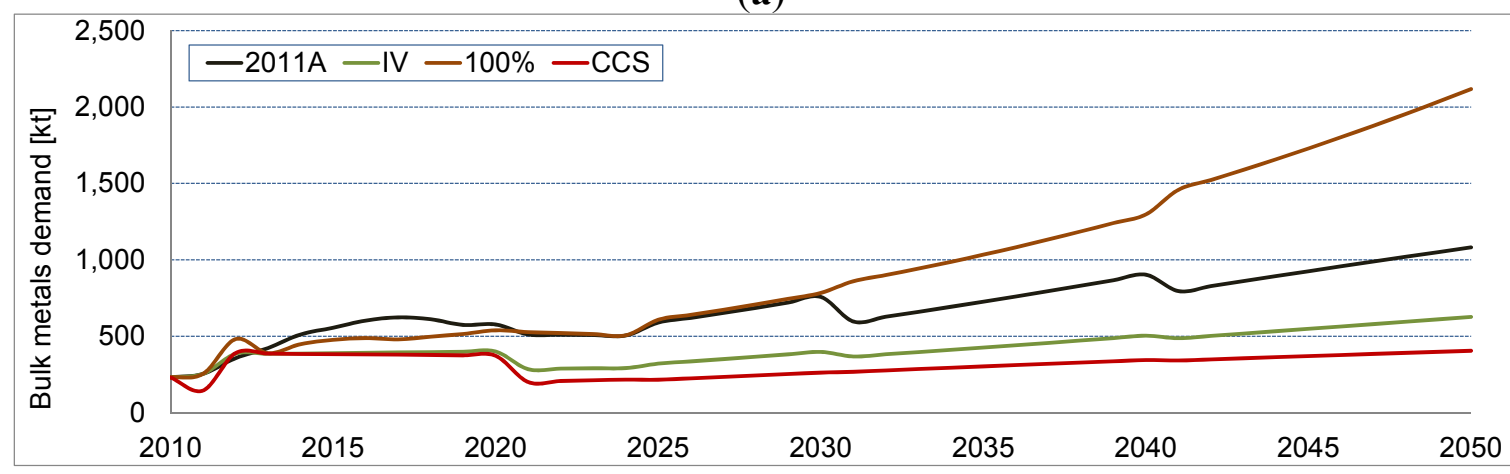

(b) 
Figure 12. Cont.

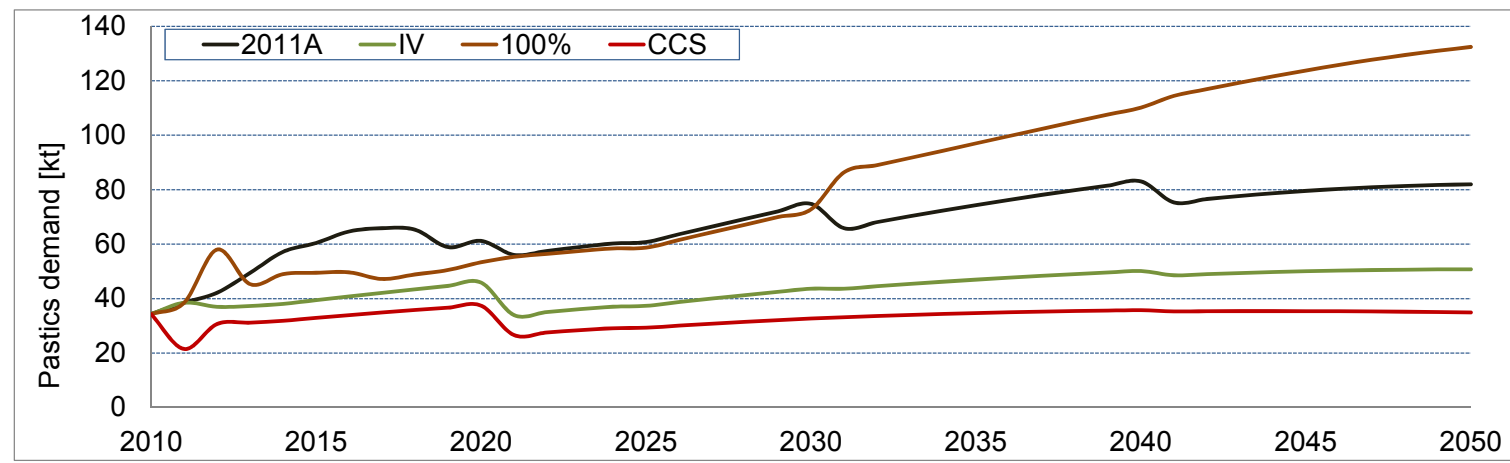

(c)

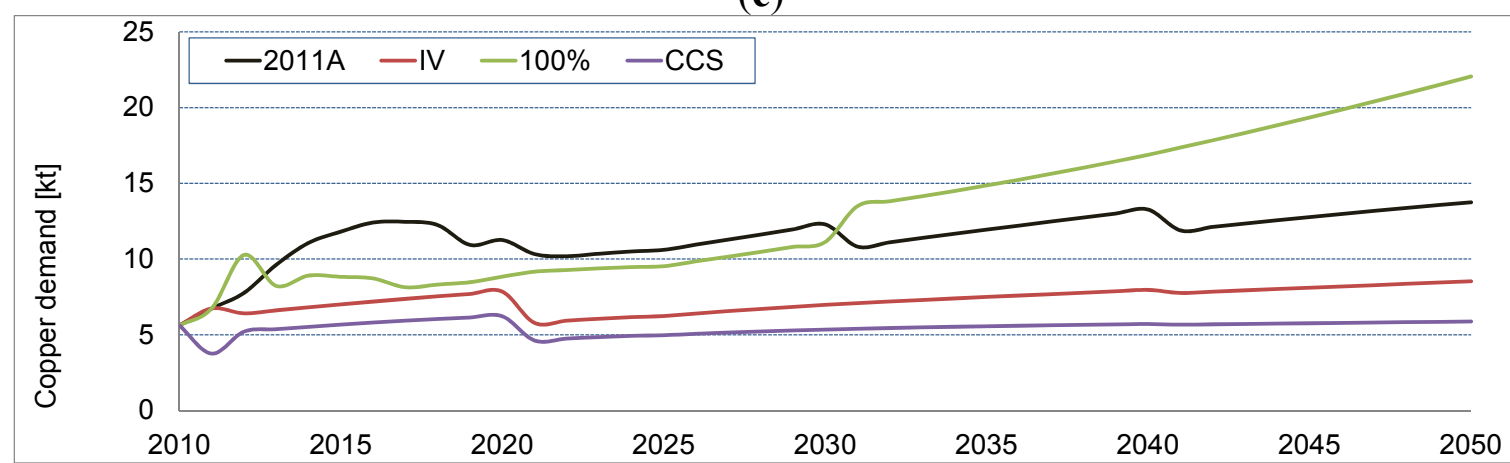

(d)

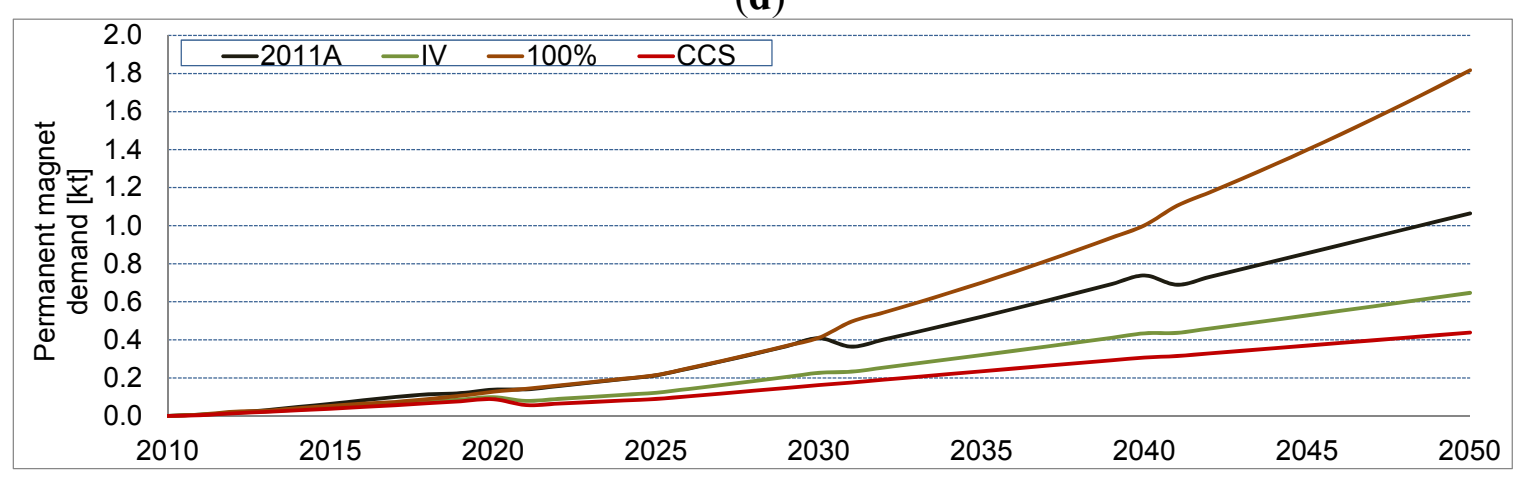

(e)

In addition, Figure 13 shows the aggregated secondary material flows resulting from dismantling of old converters for the different scenarios.

\subsection{Comparison of Future Material Demands with Current Consumption}

Table 10 shows the calculated iron, steel and aluminum demand for the years 2020, 2030, and 2050 in relation to the total 2010 consumption of these materials in Germany. Even in the $100 \%$ renewables scenario the demand for iron/steel and aluminum in 2050 will not exceed $5.8 \%$ and $1.1 \%$, respectively, of 2010's consumption of these metals. For the reference scenario (2011A) the material demands are even lower ranging from $1.5 \%$ in 2020 to $2.8 \%$ in 2050 for iron/steel, and $0.3 \%$ to $0.6 \%$ for aluminum. 
Figure 13. Secondary material flows from dismantled turbines in different scenarios.

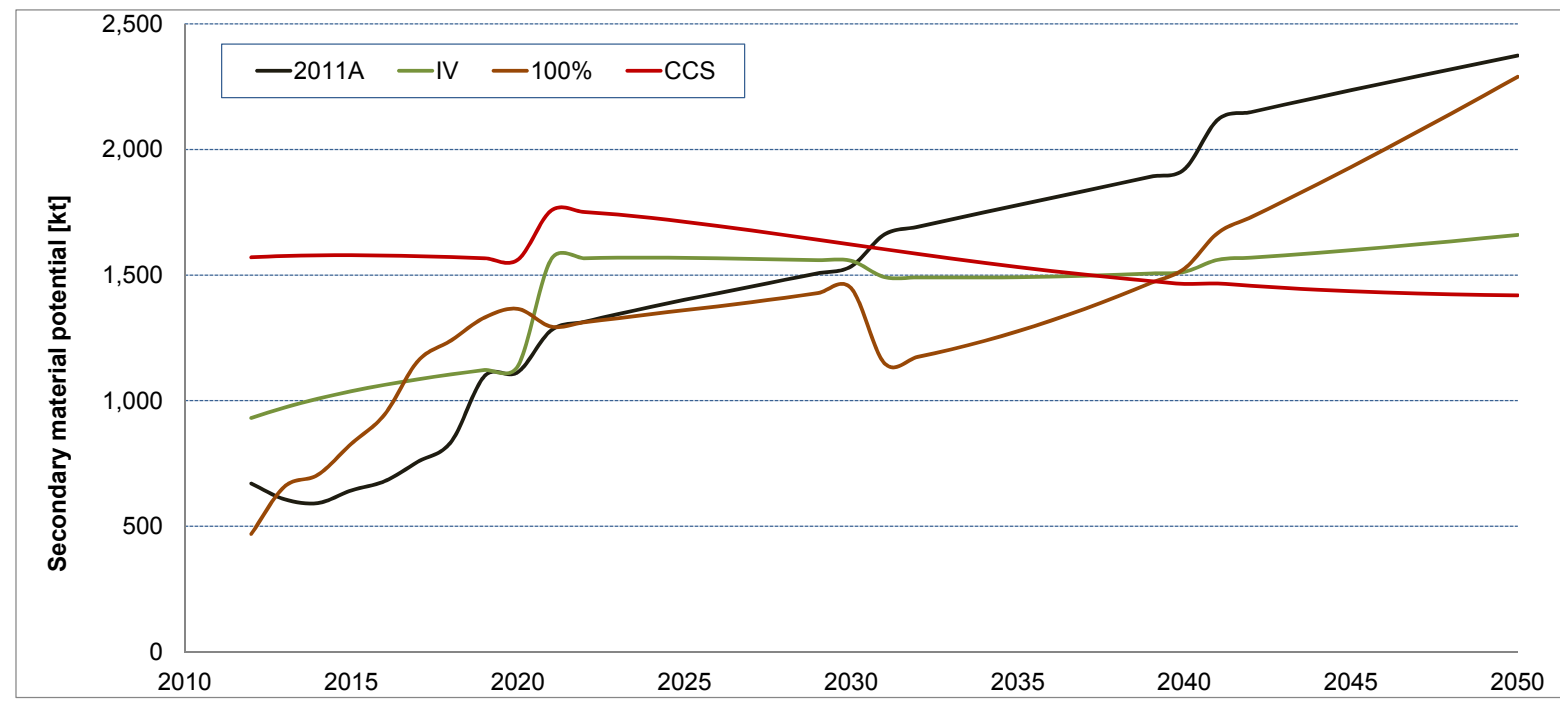

Table 10. Future steel and aluminum demand in relation to today's consumption

\begin{tabular}{cccccccccc}
\hline \multirow{2}{*}{ Material } & \multirow{2}{*}{$\begin{array}{c}\text { Consumption in } \\
\text { 2010 (Mt) [66] }\end{array}$} & \multicolumn{2}{c}{$\begin{array}{c}\text { Max. demand in } \\
\text { 2050 (100\% RE) }\end{array}$} & \multicolumn{2}{c}{$\begin{array}{c}\text { Demand in } \\
\mathbf{2 0 2 0}(\mathbf{2 0 1 1} A)\end{array}$} & \multicolumn{2}{c}{$\begin{array}{c}\text { Demand in } \\
\mathbf{2 0 3 0} \text { (2011A) }\end{array}$} & \multicolumn{2}{c}{$\begin{array}{c}\text { Demand in } \\
\text { 2050 (2011A) }\end{array}$} \\
\cline { 3 - 11 } & & Mt & Rel. to 2010 & kt & Rel. to 2010 & kt & Rel. to 2010 & kt & Rel. to 2010 \\
\hline Iron/Steel & 36.3 & 2.1 & $5.8 \%$ & 559 & $1.5 \%$ & 711 & $2.0 \%$ & 1010 & $2.8 \%$ \\
Aluminum & 2.9 & 0.032 & $1.1 \%$ & 9 & $0.3 \%$ & 11 & $0.4 \%$ & 16 & $0.6 \%$ \\
\hline
\end{tabular}

The situation for rare earths is somewhat different. The scenario with the highest demand for rare earths (100\% renewables) results in a neodymium demand of about $527 \mathrm{t}$ in 2050. According to [67] total rare earth consumption was $1800 \mathrm{t}$ in 2008 in Germany. Thus, in 2050 the neodymium demand for permanent magnets for wind turbine generators will reach about $30 \%$ of the 2008 total rare earth consumption in Germany, which can be considered a rather significant share.

The analysis of the secondary flows (see also Table 11) shows that for some of the assessed materials such as steel, iron, aluminum, and copper, the net material demand can be significantly reduced by a recovery of the secondary material becoming available at the turbines end of life. The exemplary assessment of iron/steel and aluminum shows that assuming an $80 \%$ recycling rate, the material demand can be reduced to between $1.1 \%$ and $1.5 \%$ of today's consumption of iron/steel and $0.2 \%$ to $0.3 \%$ of today's consumption of aluminum. Similar results can be obtained for copper. Therefore, it can be concluded that no shortages from the large scale deployment of wind energy will result for these materials.

Table 11. Secondary material flows of iron/steel and aluminum from dismantled turbines.

\begin{tabular}{ccccccccc}
\hline \multirow{2}{*}{ Year } & \multicolumn{2}{c}{ Sec. material flow (kt) } & \multicolumn{2}{c}{ Recycled flow $(\mathbf{8 0 \% ,}$ kt) } & \multicolumn{2}{c}{ Net demand (kt) } & \multicolumn{2}{c}{ Rel. to 2010 } \\
& Iron/Steel & Alum. & Iron/Steel & Alum. & Iron/Steel & Alum. & Iron/Steel & Alum. \\
\hline 2020 & 199 & 3.0 & 159 & 2.40 & 400 & 6.60 & $1.11 \%$ & $0.21 \%$ \\
2030 & 303 & 4.6 & 242 & 3.68 & 469 & 7.32 & $1.29 \%$ & $0.25 \%$ \\
2050 & 592 & 9.0 & 473 & 7.20 & 537 & 8.8 & $1.48 \%$ & $0.30 \%$ \\
\hline
\end{tabular}




\subsection{Total Material Requirements}

Based on the direct material demand presented in Section 3.1 and following the approach described in Section 2.7 the total input of resources for the construction and maintenance of the wind turbines is calculated for the categories abiotic materials, water, and air using the MIPS concept.

The aggregated results in these categories for all material groups are presented in Figure 14. The total input of abiotic material increases from $9531 \mathrm{kt}$ in 2020 to 16,877 kt in 2050; the water input increases from $61,246 \mathrm{kt}$ in 2020 to $102,328 \mathrm{kt}$ in 2050.

It seems to be a noteworthy fact that a growing amount of primary resources is required for maintaining the wind energy infrastructure, even if the installed capacity is reaching a saturation level. This is of course due to the necessary replacements and the maintenance inputs. Here, however, the growing availability of secondary materials is neglected and MIPS values are assumed to remain constant over time.

Figure 14. Material inputs—material groups aggregated.

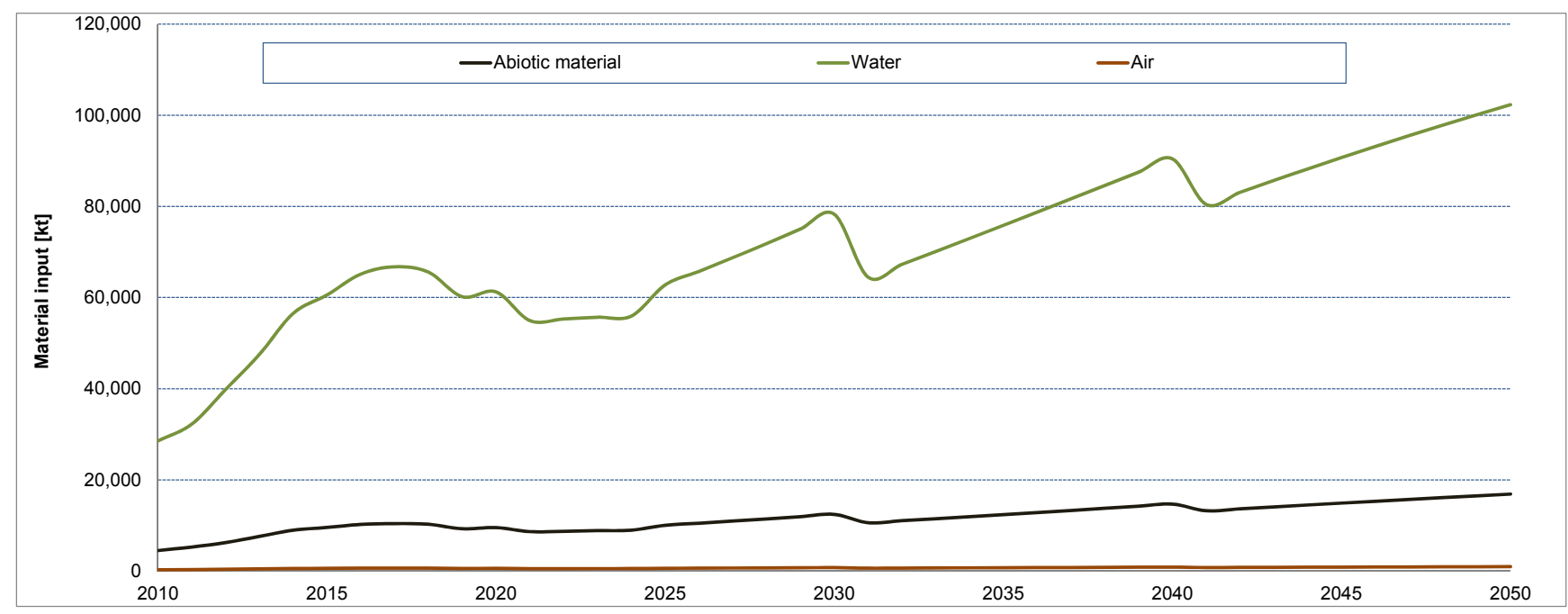

In view of the potential contribution of the ongoing energy transition towards dematerializing the German economy, it is informative to calculate the specific material intensity of electricity generated from wind energy. For the 2011A scenario we calculated the cumulated installed wind power from 2010 onwards and the cumulated material inputs. The electricity generation can be calculated by assuming future capacity factors, or full-load-hours (FLH) for wind energy installations. The average FLH for German onshore wind energy installations between 2000 and 2010 was $1483 \mathrm{~h}$ (based on data from the German Wind Energy Association BWE [68]). For offshore parks there are no such statistics available yet. However, first results from parks in the Baltic Sea and the North Sea show FLH values between 3000 and $4000 \mathrm{~h}$ (cf. [69]). For our calculations we have assumed conservative FLH values of $1450 \mathrm{~h}$ for onshore and 3500 for offshore installations. Together with the aggregated material inputs we could then determine the MIPS value for electricity produced from WEC installed between 2010 and 2050, see Figure 15. The potential contribution to dematerializing the German economy is discussed further below. 
Figure 15. Specific material intensity (MIPS) of wind energy (in $\mathrm{kg} / \mathrm{kWh}$ ) for the 2011A scenario.

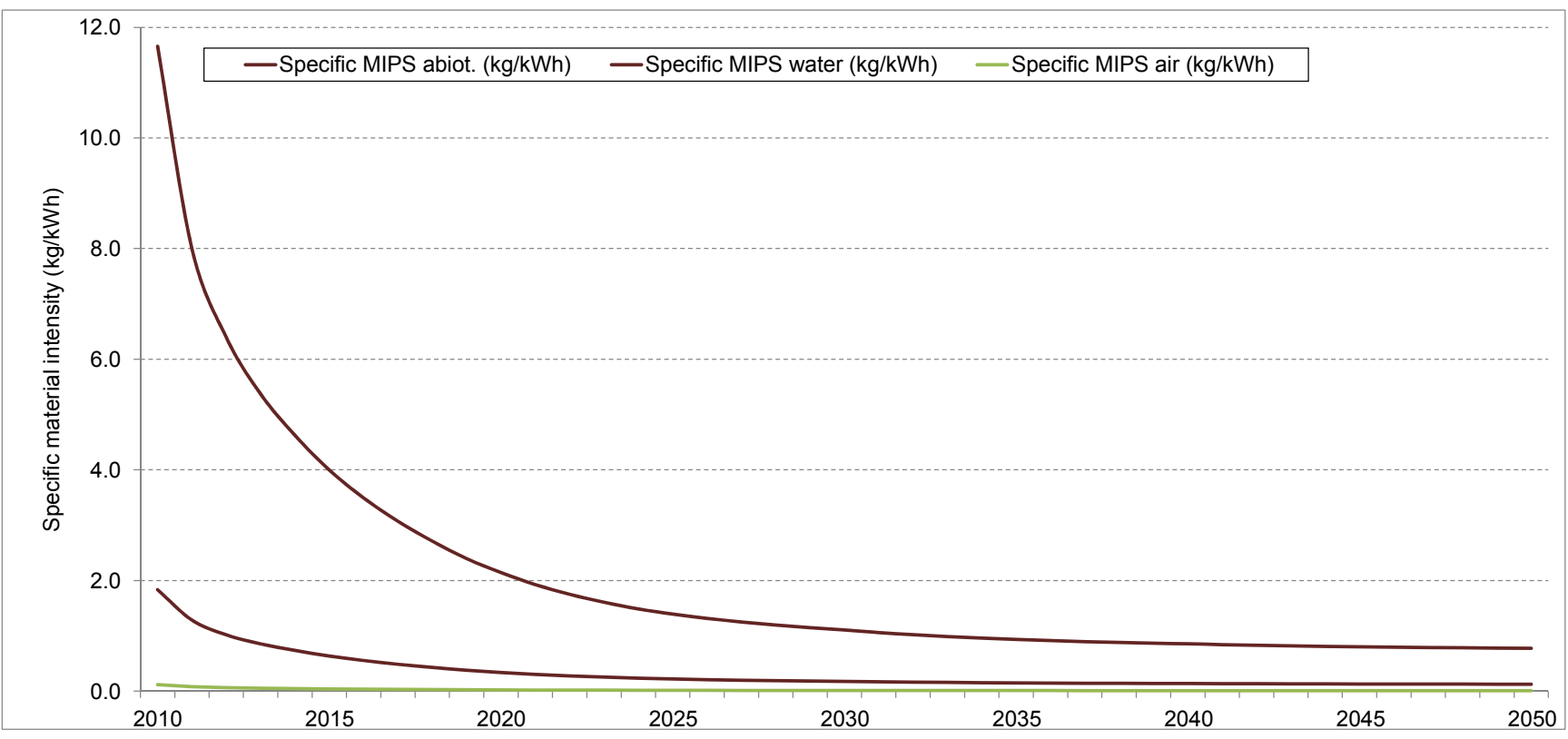

A differentiated picture of the total material requirements emerges when the direct material inputs are looked at separately. While the direct material demand was dominated by concrete, followed with some distance by the bulk metals, the application of the MIPS concept shows quite different results. Here, iron and steel are the dominant materials in terms of abiotic material and water input, growing to over $8000 \mathrm{kt}$ and 62,000 kt, respectively, until 2050. The abiotic material input for concrete grows to nearly $3000 \mathrm{kt}$, followed closely by copper. The abiotic material input for permanent magnets shows a most significant growth. While in 2010 the material input arising from permanent magnet material is almost negligible, it almost catches up with copper in 2050. Plastics show significance in terms of water use, followed by aluminum.

At this stage, we need to consider our approximations from above and its impact on the results. If the "real" MIPS value for rare earths was $50 \%$ or $150 \%$ of the assumed value, respectively, the permanent magnets' contribution to the overall abiotic material input in 2050 would be $7 \%$ and $21 \%$, respectively. The potential error introduced by using silver as a proxy for rare earths is not negligible, but it does not change the general conclusion: rare earths become relevant as a driver for the material demand of wind energy in this scenario towards the middle of the century.

\section{Discussion}

Evidently, any study of future material flows of wind energy deployment, just like for any other technology, is only as good as the underlying scenario for the future development. Especially for energy technologies these scenarios differ significantly from each other and even short term developments are not easily predicted due to unsteady political and regulatory boundary conditions. This is reflected in the differences shown between the four scenarios that have been used in this analysis. Nevertheless, we consider it appropriate to choose the 2011A scenario as a reference since it is based on most recent developments and political targets. Scenario analysis, however, should not be 
confused with prognosis. The real benefit from calculating the scenario based material demands lies in showing the consequences of certain strategic decisions on the energy system in terms of potential bottlenecks or conflicts. Based on this information decision makers can then proceed to take necessary precaution when developing policies and technologies. Apart from laying open the material consequences of certain energy policies, the wide range of the results very clearly shows the uncertainty the energy sector and its material suppliers have to deal with in the future, especially concerning rare earth metal demands.

Another potential source of uncertainty regarding the calculated material flows comes from the fact that the assumed material requirements of the wind energy technologies are not considering site specific differences (except on- and offshore). Different site specific characteristics (condition of soil, existing infrastructure, wind profile) result in differences in the material inventory. The influence of site specific parameters has been described in [70] with a focus on the energetic performance of individual converters. However, it remains to be shown, if and how these differences change the material demand on an aggregated scale. The chosen approach is based on the assumption that increases and decreases in the site-specific material demand cancel each other out and can thus be neglected. A more detailed analysis would be necessary to decide whether this assumption is justified.

Although using the Weibull distribution instead of a simultaneous exit function can be considered the more appropriate approach, it is still subject to uncertainties resulting from choosing the Weibull parameters. As stated in Section 2.6, to the authors' knowledge no studies providing actual age statistics for wind turbines have been published so far. With shape parameters for most products varying between 1 and 3 and those of long living infrastructure and industrial commodities being around 2, a shape parameter of 2 has been selected in this study. Addressing how this uncertainty affects the results, additional k-values have been tested and their influence on the modeled material flows has been identified. In addition to $k=2$, values of 1.5 and 2.5 have been used and the results are shown in Figure 16. It is evident that the influence of this parameter variation is marginal. The other Weibull parameter is fixed by the assumption on the average lifespan of wind energy converters, which is of course unknown, too, but to a lesser degree. There is currently no evidence that the lifespan deviates significantly from the assumed 20 years. Still, a statistical assessment of the validity of this assumption will have to wait until there is larger number of end-of-life converters. For the time being, we will have to trust in the accuracy of this manufacturers' estimate. However, even if the average lifespan of the converters would be off by a few $\%$, for example, $10 \%$, the above given material demand curves would only be partly shifted a few years into the future or the past, i.e., the replacement demand would be appearing earlier or later. Their principal shape, however, and the approximate size of the peaks would be retained. Based on this fact and the above discussion, we are confident that potential uncertainties regarding the Weibull parameters are not likely to have a significant influence on the calculated results. In contrast, assuming a simultaneous exit function to model the future material flows resulting from wind energy deployment leads to significantly differing results. In Figure 17, the results for the reference scenario using the Weibull distribution with an average life span of $T=20$ and a shape parameter of $k=2$ are compared to the results from using the simultaneous exit function with a life span (time span for simultaneous exit) of $T=20$. The flows obtained from assuming the simultaneous exit show very characteristic peaks in the year 2022 and 2042 (for the material demand as well as for the secondary material flows). In 2022, not only the newly installed converters, 
but also all converters installed in 2002, the year with the historically highest newly installed capacity, need replacement due to their simultaneous exit. The same occurs every 20 years. In comparison, such peaks do not occur in the Weibull graphs ( $c f$. Figure 18). Even though both approaches do not differ significantly in the total material flows (i.e., less than 5\% difference in the material demand over the considered time span), the simultaneous exit function shows severe shortcomings if it was to be used for planning purposes. Such shortcomings would, e.g., include the overestimation of expected peak material demands or the need of secondary materials processing infrastructure.

The MIPS results do not immediately reveal new information when analyzed on the aggregate level. However, when disaggregated they adequately reflect the growing "material rucksack" of different components. The MIPS results especially highlight the growing indirect material flows from permanent magnets, a fact that would otherwise be easily overlooked. Furthermore, we can conclude that wind energy does indeed significantly help to lower the material intensity of the German economy. The 2008 MIPS values for the German electricity mix are $3.15 \mathrm{~kg} / \mathrm{kWh}$ (abiotic material input), $57.64 \mathrm{~kg} / \mathrm{kWh}$ (water input) and $0.51 \mathrm{~kg} / \mathrm{kWh}$ (air input) respectively [56]. For the 2011A scenario, considering only newly installed or replaced capacity from 2010 onwards, the MIPS values for electricity generated by wind energy range from $1.83 \mathrm{~kg} / \mathrm{kWh}$ (abiotic), $11.66 \mathrm{~kg} / \mathrm{kWh}$ (water) and $0.11 \mathrm{~kg} / \mathrm{kWh}$ (air) in 2010 to $0.13,0.78$ and 0.01 , respectively, in 2050 ( $c f$. Figure 15).

Figure 16. Material inputs - (a) abiotic materials; and (b) water.

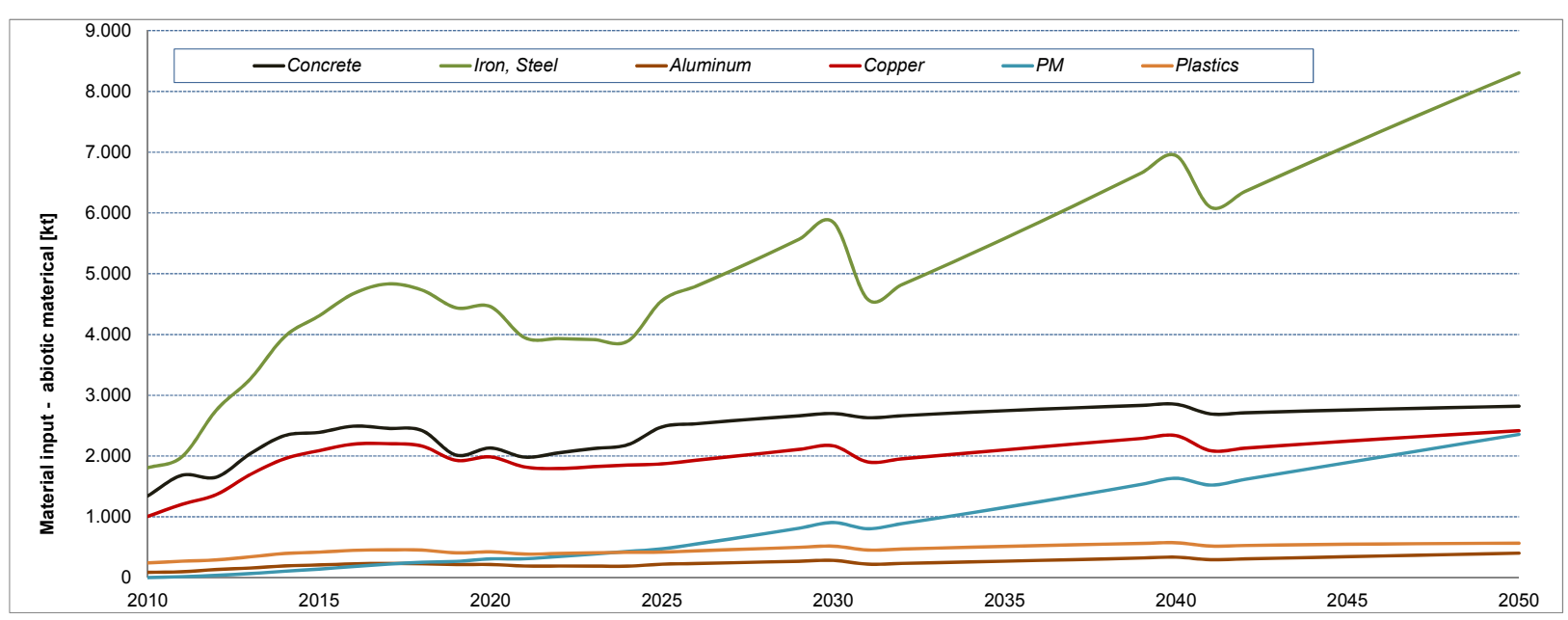

(a)

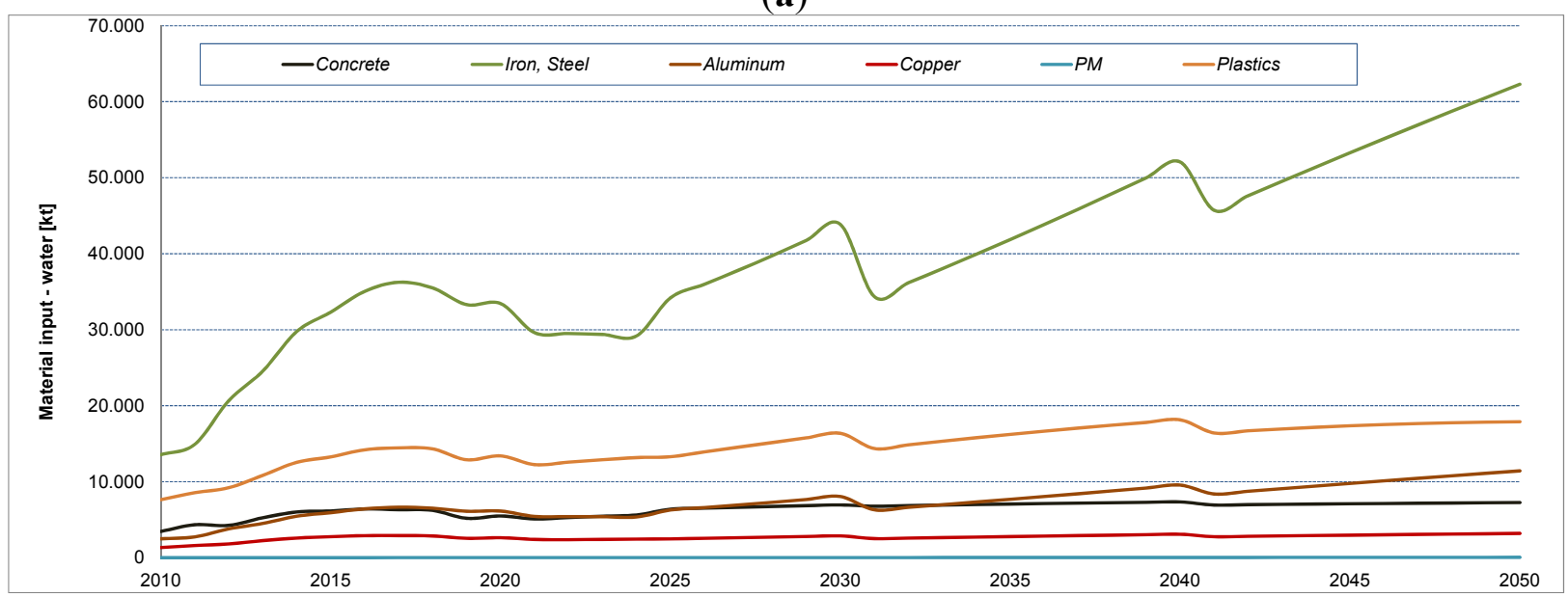

(b) 
Figure 17. Material flows from different shape parameters.

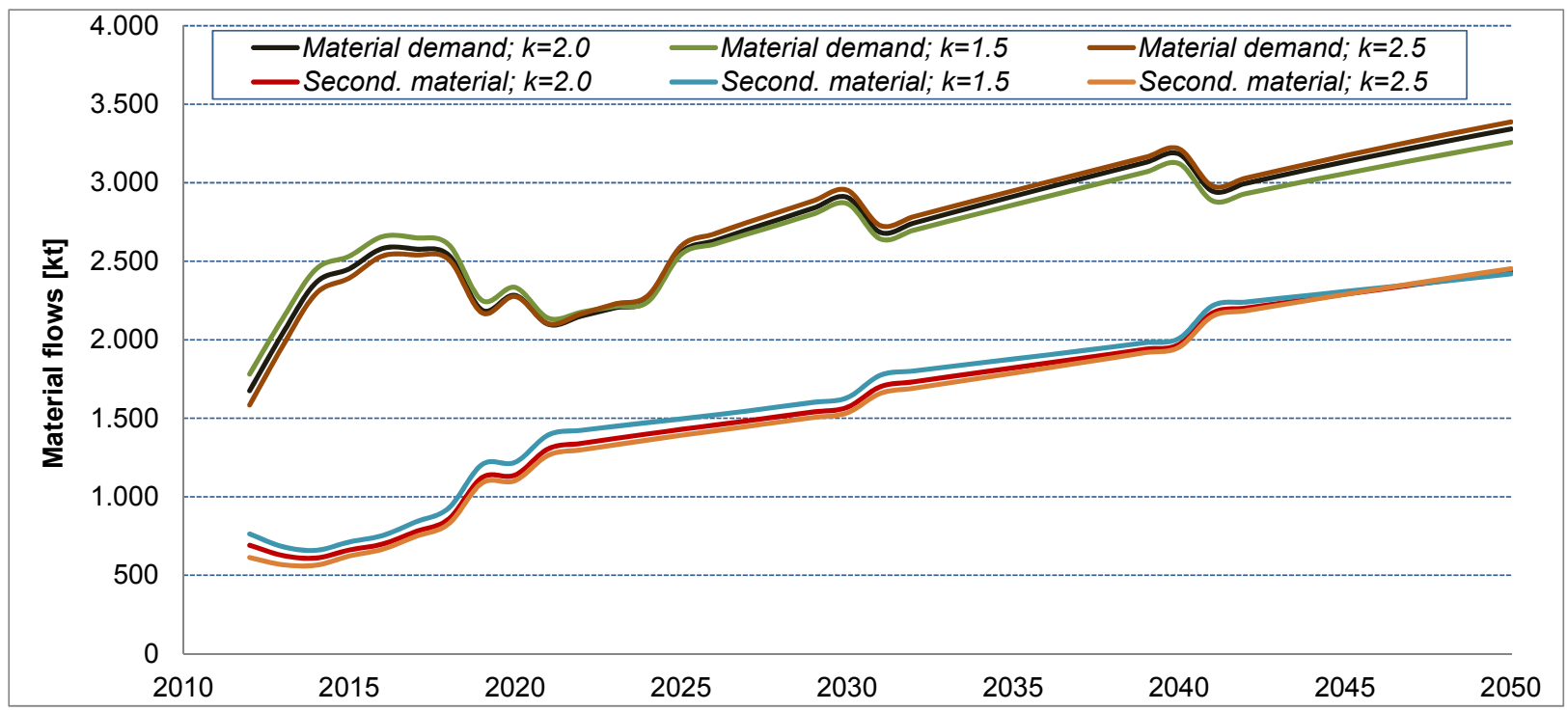

Figure 18. Comparison of material flows: Weibull function $v s$. simultaneous exit.

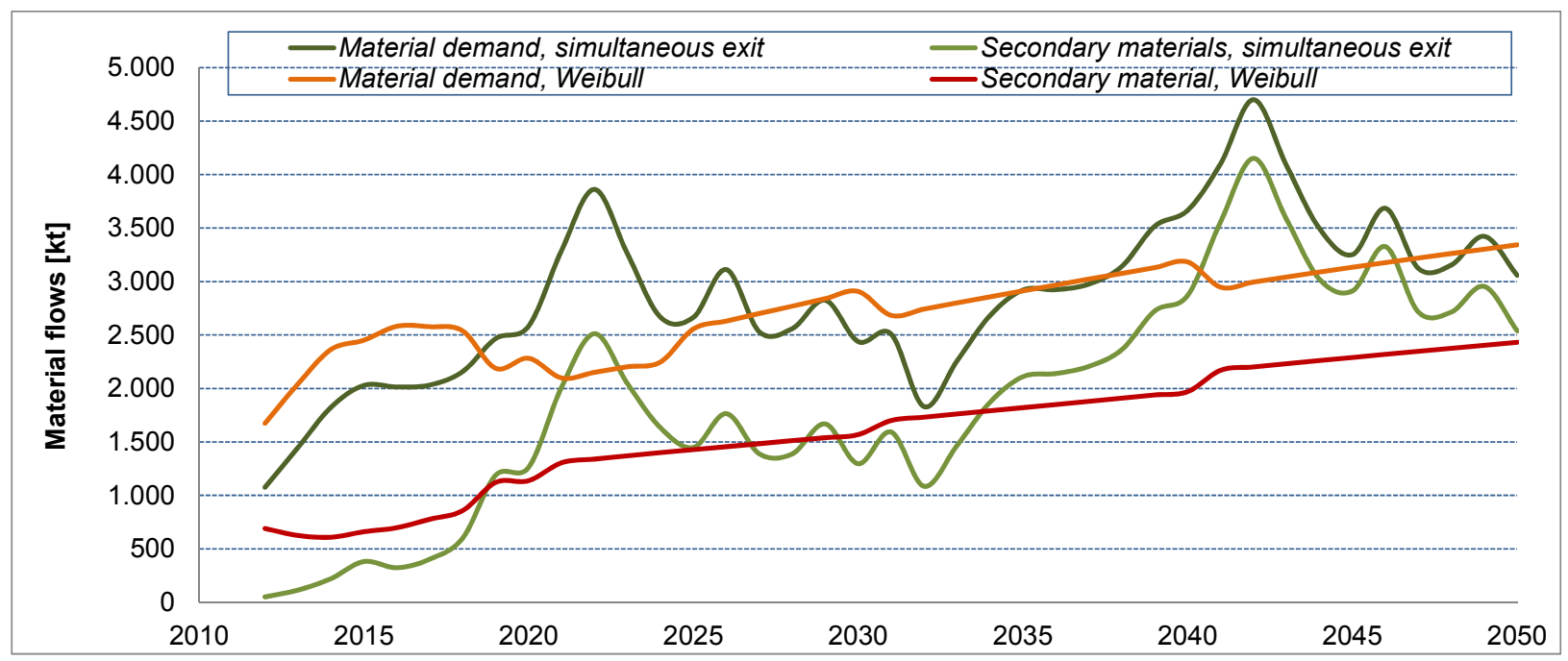

\section{Conclusions}

In the presented work, the material demand of large scale wind energy deployment in Germany has been quantified. Under the assumption that the national demand for bulk metals (aluminum, steel, copper) will not change drastically from 2010 values, we conclude that wind energy deployment in Germany will not substantially contribute to material shortages for these metals. In absolute terms, the wind energy related demand for bulk metals until 2050 grows by a factor of two up to a factor of eight compared to 2010. However, in relative terms, wind energy related demand will most likely not exceed a few percent of the total demand for these metals. Regarding material required for permanent magnets, notably the rare earths, the situation appears to be slightly different. The demand growth for these metals appears to be much more significant compared to the 2010 level. This is especially relevant because rare earths are considered critical in many studies (see [71] for a review). Criticality in most studies is defined as the combination of a materials economic importance and the risk of a 
supply shortage (see for example [19,20,59] for details on the concept of criticality). The high criticality of rare earths also arises from a higher than average environmental burden (as indicated by their specific cumulated energy demand or MIPS values as discussed in Section 3.4). Even if the criticality of rare earths itself should decrease in the future, e.g., due to new mines coming into operation, the environmental implications will pose a reason for concern and should be addressed by the manufacturers of wind energy converters. It has to be noted, that even though the criticality of neodymium and dysprosium and their role as a potential bottleneck for renewable energies are recently intensively discussed [19,59,72-74], other publications highlight the differences in the supply situation between light and heavy rare earths [75]. The situation for neodymium might turn out to be much less severe than for dysprosium, which belongs to the heavy rare earth elements. In addition, the above-mentioned opening of several new mines in the forthcoming years will significantly affect the supply situation. In addition, it has to be pointed out, that these materials are only required for a particular wind turbine type (DDPMG). Other generator designs working without permanent magnets (DFIG, DDSG) are available, which is why a substitution on the product level is possible and no general concern regarding a bottle-neck for wind energy deployment can be concluded. Again, for a complete evaluation of potential future restrictions concerning the production and installment of wind energy, the environmental burdens from mining rare earth metals have to be considered. The crude approximations made above at least signal the need for a more thorough investigation into the overall environmental effects of large scale wind energy deployment, as for example by a system wide LCA analysis (see for example [6]).

Notwithstanding the open question of the environmental burden from expanding wind energy in Germany, its growing share in the electricity mix will contribute to the dematerialization of the German economy. This conclusion seems to be robust against uncertainties around the future technology mix of wind energy, since the MIPS for wind generated electricity is so much lower than for the current system.

From a methodological side, the approach chosen here for wind energy seems readily transferrable to other renewable energy technologies, like solar energy, fuel cells, or electric vehicles. However, it must be noted that the data requirements are high and the partly poor data quality, especially for technologies in dynamic development, poses a real challenge. The assessment of future material demands would benefit enormously from advances in life-cycle assessment, especially in terms of parameterized data models, and from a more formal requirement for technology providers to supply information on the material composition of their devices. The latter would further lead to a substantial improvement for a subsequent assessment of recycling potentials and secondary material mapping as a basis for urban mining.

\section{Conflicts of Interest}

The authors declare no conflict of interest.

\section{References}

1. Global Wind Energy Council. Global Wind Report: Annual Market Update 2011; Global Wind Energy Council: Brussels, Belgium, 2012. 
2. European Wind Energy Association. Wind in Power: 2011 European Statistics; European Wind Energy Association: Brussels, Belgium, 2012.

3. Bundesverband WindEnergie e.V. Jahresbilanz Windenergie 2011 [in German]; Bundesverband WindEnergie: Berlin, Germany, 2012.

4. Nitsch, J.; Pregger, T.; Naegler, T.; Heide, D.; de Tena, D.L.; Trieb, F.; Scholz, Y.; Nienhaus, K.G.N.; Sterner, M.; Trost, T.; et al. Langfristszenarien und Strategien für den Ausbau der Erneuerbaren Energien in Deutschland bei Berücksichtigung der Entwicklung in Europa und Global: Leitstudie 2011 [in German]; Schlussbericht BMU-FKZ 03MAP146; Institut für Windenergie und Systemtechnik (Fraunhofer IWES): Stuttgart, Germany; Deutsches Zentrum für Luft und Raumfahrt (DLR): Kassel, Germany; Ingenierbüro für Erneuerbare Energien (IFNE): Teltow, Germany, 2012.

5. Kristof, K.; Hennicke, P. Final Report on the Material Efficiency and Resource Conservation (MaRess) Project; Wuppertal Institute for Climate, Environment and Energy: Wuppertal, Germany, 2010.

6. Arvesen, A.; Hertwich, E.G. Environmental implications of large-scale adoption of wind power: A scenario-based life cycle assessment. Environ. Res. Lett. 2011, 6, 045102:1-045102:9.

7. Geuder, M. Energetische bewertung von WEA: Was man über stoff- und energiebilanz von erneuerbaren energien wissen muss. Erneuerbare Energien 2004, 8, 25-29.

8. Wagner, H.-J.; Baack, C.; Eickelkamp, T.; Epe, A.; Lohmann, J.; Troy, S. Life cycle assessment of the offshore wind farm alpha ventus. Energy 2011, 36, 2459-2464.

9. Vestas Wind Systems A/S. Life Cycle Assessment of Electricity Produced from Onshore Sited Wind Power Plants Based on Vestas V82-1.65 MW Turbines; Vestas Wind Systems A/S: Randers, Denmark, 2006.

10. Vestas Wind Systems A/S. Life cycle Assessment of Offshore and Onshore Sited Wind Power Plants Based on Vestas V90-3.0 MW Turbines, 2nd ed.; Vestas Wind Systems A/S: Randers, Denmark, 2006.

11. D’Souza, N.; Gbegbaje-Das, E.; Shonfield, P. Life Cycle Assessment of Electricity Production from a V112 Turbine Wind Plant; Vestas Wind Systems A/S: Copenhagen, Denmark, 2011.

12. Garrett, P.; Rønde, K. Life Cycle Assessment of Electricity Production from a V100-1.8 MW Gridstreamer Wind Plant; Vestas Wind Systems A/S: Randers, Dänemark, 2011.

13. Zimmermann, T. Parameterized tool for site specific LCAs of wind energy converters. Int. J. Life Cycle Assess. 2013, 18, 49-60.

14. Briem, S.; Viebahn, P.; Gürzenich, D.; Corradini, R.; Blesl, M.; Fahl, U.; Ohl, M.; Moerschner, J.; Eltrop, L.; Voß, A.; et al. Lebenszyklusanalyse ausgewählter zukünftiger Stromerzeugungstechniken [in German]; IER, DLR, LEE, FfE: Stuttgart, Germany, 2004.

15. Classen, M.; Althaus, H.-J.; Blaser, J.; Tuchschmid, M.; Jungbluth, N.; Doka, G.; Faist Emmerger, M.; Scharnhorst, W. Life Cycle Inventories of Metals; Final Report Ecoinvent Data v2.1, No. 10; EMPA Dübendorf, Swiss Center for Life Cycle Inventories: Dübendorf, Switzerland, 2009.

16. Dong Energy. NEEDS - New Energy Externalities Development for Sustainability—Final Report on Offshore Wind Technology; DG Research, European Commission: Stuttgart, Germany, 2008. 
17. Geuder, M. Energetische Bewertung von Windkraftanlagen [in German]. Ph.D. Thesis, Hochschule für Angewandte Wissenschaften Würzburg-Schweinfurt, Schweinfurt, Germany, 2 April 2004.

18. Martínez, E.; Sanz, F.; Pellegrini, S.; Jiménez, E.; Blanco, J. Life cycle assessment of a multi-megawatt wind turbine. Renew. Energy 2009, 34, 667-673.

19. Catinat, M. Critical Raw Materials for the EU-Report of the Ad-Hoc Working Group on Defining Critical Raw Materials; European Commission, Enterprise and Industry: Brüssel, Belgium, 2010.

20. Erdmann, L.; Behrendt, S. Kritische Rohstoffe für Deutschland: Identifikation aus Sicht Deutscher Unternehmen Wirtschaftlich Bedeutsamer Mineralischer Rohstoffe, deren Versorgungslage sich Mittel- bis Langfristig als kritisch erweisen könnte [in German]; Institut für Zukunftsstudien und Technologiebewertung: Berlin, Germany, 2011.

21. Molly, J. DEWI Statistiken der Jahre 2000-2011 [in German]; DEWI GmbH: Wilhelmshaven, Germany. Available online: http://www.dewi.de/dewi/index.php?id=47\&L=1 (accessed on 10 September 2012).

22. Polinder, H.; van der Pijl, F.; de Vilder, G.-J.; Tavner, P. Comparison of Direct-Drive and Geared Generator Concepts for Wind Turbines. In Proceedings of 2005 IEEE International Conference on Electric Machines and Drives, San Antonio, TX, USA, 15 May 2005; pp. 543-550.

23. Woidasky, J.; Seiler, E.; Stolzenberg, A. Recycling von Windkraftanlagen; Fraunhofer ICT: Berlin, Germany, 2010.

24. Weinzettel, J.; Reenaas, M.; Solli, C.; Hertwich, E.G. Life cycle assessment of a floating offshore wind turbine. Renew. Energy 2009, 34, 742-747.

25. Davies, B.E.; Mottram, R.S.; Harris, I.R. Recent developments in the sintering of NdFeB. Mater. Chem. Phys. 2001, 67, 272-281.

26. Zimmermann, T. Entwicklung eines Life Cycle Assessment Tools für Windenergieanlagen [in German]. Master's Thesis, University of Bremen, Bremen, Germany, 11 January 2011.

27. Oberwahrenbrock, F.; Schneider, M.; Wöginger, A.; Wohlmann, B. Uni-Directional Fibre Preform Having Slivers and Consisting of Reinforcing Fibre Bundles, and a Composite Material Component. Australia Patent AU2011335297, 11 November 2011.

28. Echavarria, E.; Hahn, B.; van Bussel, G.J.; Tomiyama, T. Reliability of wind turbine technology through time. J. Sol. Energy Eng. 2008, 130, 031005:1-031005:8.

29. Krüder, K. Life-Cycle-Konzepte; Voith Industrial Services Wind GmbH: Hanover, Germany 2009.

30. Arabian-Hoseynabadi, H.; Oraee, H.; Tavner, P.J. Failure Modes and Effects Analysis (FMEA) for wind turbines. Int. J. Electr. Power Energy Syst. 2010, 32, 817-824.

31. Caduff, M.; Huijbregts, M.A.J.; Althaus, H.-J.; Koehler, A.; Hellweg, S. Wind power electricity: The bigger the turbine, the greener the electricity? Environ. Sci. Technol. 2012, 46, 4725-4733.

32. Zimmermann, T. Fully Parameterized LCA Tool for Wind Energy Converters. In Proceedings of the Life Cycle Management Conference 2011, Berlin, Germany, 28-31 August 2011.

33. Molly, J. Status der Windenergienutzung in Deutschland-Stand 31.12.2011. Available online: http://www.wind-energie.de/sites/default/files/attachments/press-release/2011/deutsche-windindustriemaerkte-erholen-sich/windenergie-deutschland-langfassung.pdf (accessed on 19 September 2012). 
34. Schlesinger, M.; Lindenberger, D.; Lutz, C. Energieszenarien 2011 [in German]; Study on Behalf of the German Ministry for Economy and Technology; Prognos AG: Basel, Switzerland; Energiewirtschaftliches Institut der Universität Köln (EWI): Cologne, Germany; Geselleschaft für Wirtschaftliche Strukturforschung mbH (GWS): Osnabrück, Germany, 2011.

35. Kirchner, A.; Matthes, F. Modell Deutschland. Klimaschutz bis 2050: Vom Ziel her Denken [in German]; Institute for Applied Ecology: Berlin, Germany, 2009.

36. Nitsch, J.; Pregger, T.; Scholz, Y.; Naegler, T.; Sterner, M.; Gerhard, N.; von Oehsen, A.; Pape, C.; Saint-Drenan, Y.-M.; Wenzel, B. Leitstudie 2010-Langfristszenarien und Strategien für den Ausbau der Erneuerbaren Energien in Deutschland bei Berücksichtigung der Entwicklung in Europa und Global [in German]; BMU-FKZ 03MAP146; Institut für Windenergie und Systemtechnik (Fraunhofer IWES): Stuttgart; Deutsches Zentrum für Luft und Raumfahrt (DLR): Kassel; Ingenieurbüro für erneuerbare Energien (IFNE): Teltow, Germany, 2010.

37. Fraunhofer Institut für Windenergie und Energiesystemtechnik (IWES). Windenergie Report Deutschland 2011; IWES: Kassel, Germany, 2012. Available online: http://windmonitor.iwes.fraunhofer.de/bilder/upload/Windreport_2011_de.pdf (accessed on 17 September 2012).

38. Abrahamsen, A.B.; Mijatovic, N.; Seiler, E.; Zirngibl, T.; Træholt, C.; Nørgård, P.B.; Pedersen, N.F.; Andersen, N.H.; Østergård, J. Superconducting wind turbine generators. Supercond. Sci. Technol. 2010, 23, 034019:1-034019:8.

39. Jamieson, P. Innovation in Wind Turbine Design; Wiley: Chichester, UK, 2011.

40. European Wind Energy Association (EWEA). UpWind: Design Limits and Solutions for Very Large Wind Turbines; EWEA: Brussels, Belgium, 2011.

41. Marsh, G. Wind turbines. Refocus 2005, 6, 22-28.

42. Michel, S. Permanentmagnetgeneratoren im Trend. Available online: http://www.windkraftkonstruktion.vogel.de/triebstrang/articles/289412/ (accessed on 30 November 2012).

43. Organisation for Economic Co-Operation and Development (OECD). Measuring Capital_OECD Manual: Measurement of Capital Stocks, Consumption of Fixed Capital and Capital Services; OECD: Paris, France, 2001.

44. Wilker, H. Leitfaden zur Zuverlässigkeitsermittlung technischer Komponenten: Mit 86 Tabellen, 86 Beispielen [in German], 2nd ed; Books on Demand: Norderstedt, Germay, 2010.

45. Gößling-Reisemann, S.; Knak, M.; Björn, S. Lifetimes and Copper Content of Selected Obsolete Electric and Electronic Products. In Resource Management and Technology for Material and Energy Efficiency, Proceedings of R'09 Twin World Congress, Dübendorf, Switzerland, 14-16 September 2009.

46. Oguchi, M.; Kameya, T.; Yagi, S.; Urano, K. Product flow analysis of various consumer durables in Japan. Resour. Conserv. Recycl. 2008, 52, 463-480.

47. Tasaki, T.; Takasuga, T.; Osako, M.; Sakai, S.-I. Substance flow analysis of brominated flame retardants and related compounds in waste TV sets in Japan. Waste Manag. 2004, 24, 571-580.

48. Kagawa, S.; Tasaki, T.; Moriguchi, Y. The environmental and economic consequences of product lifetime extension: Empirical analysis for automobile use. Ecol. Econ. 2006, 58, 108-118. 
49. Nomura, K. Duration of Assets: Examination of Directly Observed Discard Data in Japan; KEO Discussion Paper No. 99; Keio Economic Observatory, Keio University: Tokyo, Japan, 2005.

50. Ortegon, K.; Nies, L.F.; Sutherland, J.W. Preparing for end of service life of wind turbines. J. Clean. Prod. 2013, 39, 191-199.

51. Law, A.M. Simulation Modeling and Analysis, 4th ed.; McGraw-Hill: Boston, MA, USA, 2007.

52. National Institute for Environmental Studies (NIES) Web Page. Lifespan Database for Vehicles, Equipment, and Structures: LiVES. Available online: http://www.nies.go.jp/lifespan/index-e.html (accessed on 30 January 2013).

53. Wagner, H.-J.; Epe, A. Energy from wind-Perspectives and research needs. Eur. Phys. J. Spec. Top 2009, 176, 107-114.

54. Ritthoff, M.; Rohn, H.; Liedtke, C. Calculating MIPS: Resource Productivity of Products and Services; Wuppertal Institute for Climate, Environment and Energy: Wuppertal, Germany, 2002.

55. Bringezu, S.; Schütz, H.; Moll, S. Rationale for and interpretation of economy-wide materials flow analysis and derived indicators. J. Ind. Ecol. 2003, 7, 43-64.

56. Wuppertal Institute for Climate, Environment and Energy. Material Intensity of Materials, Fuels, Transport Services, Food [in German]. Available online: http://wupperinst.org/uploads/ tx_wupperinst/MIT_2011.pdf (accessed on 3 December 2012).

57. Huijbregts, M.A.J.; Hellweg, S.; Frischknecht, R.; Hendriks, H.W.M.; Hungerbühler, K.; Hendriks, A.J. Cumulative energy demand as predictor for the environmental burden of commodity production. Environ. Sci. Technol. 2010, 44, 2189-2197.

58. Althaus, H.-J.; Hischier, R.; Osses, M.; Primas, A. Life Cycle Inventories of Chemicals; Final Report Ecoinvent Data v2.0 No. 8; EMPA, Swiss Centre for Life Cycle Inventories: Dübendorf, Switzerland, 2007.

59. Moss, R.L.; Tzimas, E.; Kara, H.; Kooroshy, J. Critical Metals in Strategic Energy Technologies: Assessing Rare Metals as Supply-Chain Bottlenecks in Low-Carbon Energy Technologies; JRC Scientific and Technical Reports JRC65592; Publications Office of the European Union: Luxembourg, 2011.

60. Talens Peiro, L.; Villalba Mendez, G.; Ayres, R.U. Rare and Critical Metals as By-Products and the Implications for Future Supply; Working Paper; INSEAD: Paris, France, 2011.

61. Rao, S.R. Resource Recovery and Recycling from Metallurgical Wastes; Elsevier: Amsterdam, The Netherlands, 2006.

62. Hitachi Web Page. Hitachi Develops Recycling Technologies for Rare Earth Metal. Available online: http://www.hitachi.com/New/cnews/101206.html (accessed on 3 December 2012).

63. World Business Council for Sustainable Development Cement Sustainability Initiative Home Page. Available online: http://www.wbcsdcement.org/ (accessed on 3 December 2012).

64. Schmidl, E.; Hinrichs, S. Geocycle provides sustainable recycling of rotor blades in cement plant. DEWI Magazin 2010, 36, 6-14.

65. Tryfonidou, R. Energetische Analyse eines Offshore-Windparks unter Berücksichtigung der Netzintegration [in German]. Ph.D. Thesis, Ruhr University Bochum, Bochum, Germany, 20 December 2006. 
66. Babies, H.-G.; Buchholz, P.; Homberg-Neumann, D.; Huy, D.; Messner, J.; Neumann, W.; Röhling, S.; Schauer, M.; Schmidt, S.; Schmitz, M.; et al. Deutschland-Rohstoffsituation 2010 [in German]; Bundesanstalt für Geowissenschaften und Rohstoffe, Deutsche Rohstoffagentur (DERA): Hanover, Germany, 2011.

67. Schüler, D.; Buchert, M.; Liu, R.; Dittrich, S.; Merz, C. Study on Rare Earths and Their Recycling; Final Report for The Greens/EFA Group in the European Parliament; Ökoinstitut e.V.: Darmstadt, Germany, 2011.

68. German Wind Energy Association Web Page. Statistics. Available online: http://www.wind-energie.de/en/infocenter/statistics/germany (accessed on 10 August 2013).

69. Berkhout, V.; Faulstich, S.; Görg, P.; Kühn, P.; Linke, K.; Lyding, P.; Pfaffel, S.; Rafik, K.; Rohrig, K.; Rothkegel, R.; et al. Wind Energy Report Germany 2012; Fraunhofer-Institut für Windenergie und Energiesystemtechnik (IWES): Kassel, Germany, 2012.

70. Zimmermann, T.; Gößling-Reisemann, S. Influence of site specific parameters on environmental performance of wind energy converters. Energy Procedia 2012, 20, 402-413.

71. Erdmann, L.; Graedel, T.E. Criticality of non-fuel minerals: A review of major approaches and analyses. Environ. Sci. Technol. 2011, 45, 7620-7631.

72. Buchert, M. Rare Earths-A Bottleneck for Future Wind Turbine Technologies. Presented at the Conference "Wind Turbine Supply Chain \& Logistics", Berlin, Germany, 29 August 2011.

73. Buchert, M.; Schüler, D.; Bleher, D. Critical Metals for Future Sustainable Technologies and their Recycling Potential; Division of Technology, Industry and Economics, United Nations Environment Programme: Paris, France, 2009.

74. U.S. Department of Energy. Critical Materials Strategy; U.S. Department of Energy: Washington, DC, USA, 2012.

75. Elsner, H. Kritische Versorgungslage mit Schweren Seltenen Erden: Entwicklung "Grüner Technologien” Gefährdet? [in German]; Commodity Top News 36; Bundesanstalt für Geowissenschaften und Rohstoffe, Deutsche Rohstoffagentur (DERA): Hannover, Germany, 2011.

(C) 2013 by the authors; licensee MDPI, Basel, Switzerland. This article is an open access article distributed under the terms and conditions of the Creative Commons Attribution license (http://creativecommons.org/licenses/by/3.0/). 